\title{
Effects of In-Situ Poling and Process Parameters on Fused Filament Fabrication Printed PVDF Sheet Mechanical and Electrical Properties
}

Daniel A. Porter ${ }^{1}$, Trung V.T. Hoang ${ }^{2}$, and Thomas A. Berfield ${ }^{3}$

1 Post Doctorial Research Assistant

Southern Methodist University

Department of Mechanical Engineering

Dallas, TX 75206

daporter@smu.edu

2 Graduate Research Assistant

University of Louisville

Department of Mechanical Engineering

Louisville, KY 40292

trung.hoang@louisville.edu

3 Associate Professor

University of Louisville

Department of Mechanical Engineering

Louisville, KY 40292

tom.berfield@louisville.edu

(C) 2016. This manuscript version is made available under the Elsevier user license http://www.elsevier.com/open-access/userlicense/1.0/ 


\begin{abstract}
Polyvinylidene fluoride (PVDF) is a polymer prized for its unique material properties, including a high resistance to corrosive acids such as HCL and HF and its piezoelectric potential based on the proper microstructure arrangement. In this work, the effects of fused filament fabrication (FFF) routine parameters on printed PVDF film properties were investigated using a variety of experimental methods. The influence of in-fill angle $\left(0^{\circ}, 45^{\circ}\right.$, and $\left.90^{\circ}\right)$ on the effective Young's Modulus, Poisson's ratio, and yield strength were evaluated using tensile testing and a digital image correlation (DIC) analysis. The phase content, in particular the $\beta$-phase amount, within the semi-crystalline PVDF films was determined as a function of processing parameters using the FTIR method. Considered parameters included the extrusion temperature, horizontal speed, in-situ applied hot end voltage, and bed material. Results showed that higher $\beta$-phase content was associated with lower extrusion temperatures, faster extrusion rates, and higher hot end voltages. While all "as printed" films demonstrated little to no measurable piezoelectricity, PVDF films printed with a high $\beta$-phase content and subjected to a post-printing corona poling procedure showed a small, but consistent piezoelectric response. Based on a static deflection cantilever beam experiment, the $d_{31}$ coefficient of the poled specimens was estimated at 1.19 $\mathrm{pm} / \mathrm{V}$.
\end{abstract}

Keywords: piezoelectric; 3D printing; additive manufacturing; polyvinylidene fluoride; PVDF 


\section{Introduction}

Additive manufacturing techniques enable rapid prototyping of components with clever design routines and minimal post processing. Recent advances in the field of 3D printing include Carbon3D's CLIP technology for exceptionally fast printing [1], Functionalize F-Electric conductive filament with $0.75 \mathrm{ohm}-\mathrm{cm}$ resistivity, and additive manufacturing with glass [2]. Fabrication of 3D parts has not only found profitability in industrial scenes but recently fused filament fabrication (FFF) printers have become a home commodity due to reduced cost and expired patents. Any added ability to 3D fabrication methods enhances rapid prototyping commerce and bolsters human creativity.

Smart sensing materials that are compatible with additive manufacturing techniques can be exploited to augment parts with sensing, actuation, or charge generating capabilities. Polyvinylidene fluoride (PVDF) is a pseudo crystalline polymer that is piezoelectric if processed under conditions that produce the proper microstructure. The TGTG' $\alpha$-phase is the most energetically stable, but possess very weak piezoelectric properties when compared to the highly polar TTTT $\beta$-phase. Some methods of creating piezoelectric PVDF include hot pressing [3], stretching [4] [5] [6], Langmuir-deposition methods [7], and electro-spraying [8]. When fabricating PVDF sheets in the thin film regime ( $<10$ microns) through gel casting, $\beta$-phase content can be controlled by solvent type, spin speed, drying temperature, humidity, pressure, and annealing temperature/atmosphere [9] [10].

Three-dimensional construction of small piezoelectric polymer structures using digital projection printing has been investigated by Kim, et al. [11]. In their work polyethylene (glycol) diacrylate (PEGDA), barium titanate $\left(\mathrm{BaTiO}_{3}, \mathrm{BTO}\right)$, and 3-(trimethoxysilyl)propyl methacrylate (TMSPM) were combined to form $\mu \mathrm{m}$ size structures. Non-patterned films had a piezoelectric $d_{33}$ of $39 \mathrm{pC} \mathrm{N}^{-1}$ after poling, though the geometry of the films was not specified. Lee et al. investigated electric poling-assisted additive manufacturing (EPAM) with PVDF [12]. By applying a voltage to the hot end of a 3D printer, Lee's group was able to acquire individual piezoelectric PVDF extradite fibers that generated charge when flexed. In addition, Bian, et al., created a PVDF covered metal molybdenum fiber, electrically poled the structure, and then used the fiber as an air flow sensor [13]. Voltage responses for Bian's $10 \mathrm{~mm}$ long $0.4 \mathrm{~mm}$ diameter fibers were in the 100's of $\mu \mathrm{V}$ range for air flow rates of 0 to $18 \mathrm{~m} \mathrm{~s}^{-1}$. Saari, et al., enabled sensing and actuation by directly encapsulating conductive wire into a molten flexible plastic via a fiber feeding mechanism [14]. This allowed for in situ construction of coils that, as the author points out, could be enhanced further by $3 \mathrm{D}$ printing magnetic materials.

Bandyopadhyay et al. [15] created piezoelectric composites and ceramics utilizing three different rapid prototyping techniques; fused deposition of ceramics (FDC), lost mold, and soft tooling. FDC processing incorporated 50-55 volume percent PZT-5H into $1.75 \mathrm{~mm}$ filament that was then used to print green ceramic structures. Lost mold fabrication was done by printing a negative with a typical thermoplastic polymer, filling it with a PZT slurry, and then allowing it to dry. Soft tooling required 3D printing of the original part, making a silicone RTV mold of that part, injecting the mold with a thermoplastic binder loaded with PZT-5H, and then letting it cool before removing the part. All samples were processed at $500-550^{\circ} \mathrm{C}$ to remove binder and then sintered at around $\sim 1,300^{\circ} \mathrm{C}$. Sintered parts were filled with epoxy, electroded, and corona poled at $25 \mathrm{kV}$ and $70^{\circ} \mathrm{C}$ for $15-20$ minutes. Bandyopadhyay measured a $\mathrm{d}_{33}$ of up to $550 \mathrm{pC} / \mathrm{N}$ using these fabrication methods.

Gaytan et al. [16] fabricated piezoelectric barium titanate $\left(\mathrm{BaTiO}_{3}\right)$ parts by jetting a binder material over fine powder $\mathrm{BaTiO}_{3}$, sintering the parts, and then poling the resulting 
samples in an oil bath for two hours at $2 \mathrm{kV} / \mathrm{cm}$ and $120^{\circ} \mathrm{C}$. Although shrinkage values were high, specimens sintered at $1400^{\circ} \mathrm{C}$ showed a high $\mathrm{d}_{33}$ coefficient of $74.1 \mathrm{pC} / \mathrm{N}$.

Unlike other common piezoelectric materials, PVDF does not require high processing temperatures [17] when compared to electroceramics like PZT $\left(\sim 600^{\circ} \mathrm{C}+\right)$ and can be extruded instead of sputtered like aluminum nitride [18]. The processing melt temperature for PVDF is on par with current open source FFF processes $170-200^{\circ} \mathrm{C}$ [19]. PVDF homopolymer is also relatively inexpensive when compared to other fluoropolymers [20], making it an ideal candidate for commercial and hobbyist printing material.

In this research, 3D printed FFF PVDF thick films are fabricated under different processing parameters, including in situ electrical poling. A custom hot end is constructed so that a high electric field can be applied between the brass nozzles and the grounded bed. In addition, select specimens are subjected to a post-printing corona poling procedure to probe for potential piezoelectric performance enhancement. Properties for the thick PVDF films are evaluated through tensile testing, FTIR characterization, and piezoelectric response measurements.

\section{Experimental Methods \\ 2.1. Equipment and Materials}

A Reprap Prusa i3 fused filament 3D printer has been modified to accommodate a high voltage on the hot end mechanism and a ground plane on the construction bed platform. The thermistor on an E3D v5 hot end is electrically isolated by applying Kapton tape around any exposed metal leads. The glass part of the thermistor is then placed on the outside of the heating block and then insulated using fiberglass insulation tape and a generous amount of Kapton wrapping. A glass plate 3mm thick is covered in Fasson 2" aluminum duct tape with connecting conductive copper tape strips. Before applying an adhesion/electrical isolation layer of Kapton (50 $\mu \mathrm{m}$ thick) or $3 \mathrm{M}$ Scotch Blue Painter Tape $(110 \mu \mathrm{m}$ thick), the ground plane is tested for continuity. All surfaces were cleaned using an acetone, 2-propynol, and DI water routine. Additional extruder specifications are shown in Table 1.

Table 1. Extruder specifications.

Specification

\begin{tabular}{lc}
\hline Hot End Type & E3D v5 \\
Thermistor Location & Side of Heat Block \\
Nozzle Geometry & Sharp \& Flat Bottom \\
Nozzle Diameter (mm) & 0.35 \\
Max Voltage, Kapton Bed (V) & 1750 \\
Max Voltage, 3M Bed (V) & 1000 \\
PVDF Filament Diameter (mm) & $1.75 \pm 0.15$ \\
\hline
\end{tabular}

Homopolymer PVDF (Kynar 740) resin pellets were obtained from Trident Plastics Inc. and extruded in a solvent cleaned Filastruder that processed the plastic at a temperature of $220^{\circ} \mathrm{C}$ which gave a fairly consistent $1.75 \pm 0.15 \mathrm{~mm}$ filament diameter. Since the filament was air cooled the filament tended to be oval and not purely cylindrical. To purge and clean the system, 20 meters of filament was processed until the PVDF was a consistent semitransparent white 
color. Afterwards a spool of 250 grams was produced to be used in the following experiments below.

Extrusion of the PVDF filament was performed using a direct drive extruder and an E3D hot end via two different types of nozzles. One brass nozzle is conical and gave a good localized electric field across the molten PVDF film as it is extruded. The other brass nozzle was a custom flat head which was designed to give a very uniform electric field over the molten PVDF as the material was deposited. In addition, this custom nozzle aligned the molecular dipoles in the parts of the film already extruded as it traversed the applied sheet. Pictures of the modified grounded bed with Kapton, 3M tape, and the hot end with two different nozzle geometries are shown in Figure 1. Unless otherwise noted, an adhesive promoter (AquaNet) is used on top of the Kapton or $3 \mathrm{M}$ tape.

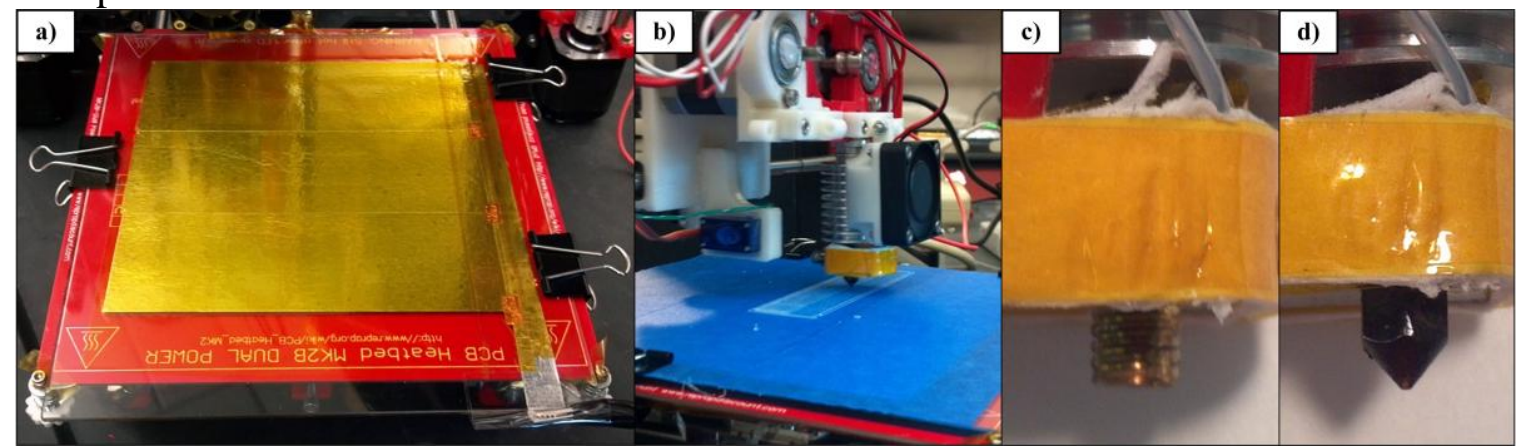

Figure 1. Grounded build platform with a) $25 \mu \mathrm{m}$ Katpon, b) $3 \mathrm{M}$ blue painters tape, c) hot end with flat nozzle, and d) hot end with sharp nozzle.

\subsection{Mechanical Properties}

Thin dog bone structures were printed under various parameters for mechanical property testing. Processing parameters varied included sample length, infill angle, and number of outside perimeters as shown in Table 2. Thicknesses for the grips of the printed sample are about twice the initial thickness. These dog bone structures are shown in Figure 2a.

Table 2. Samples used for mechanical property testing. All sample widths are $10 \mathrm{~mm}$ and

\begin{tabular}{c|c|c|c|c} 
& \multicolumn{4}{|c}{ extruded at $200^{\circ}$ C. } \\
Sample \# & $\begin{array}{c}\text { Length } \\
(\mathrm{mm})\end{array}$ & $\begin{array}{c}\text { \# of } \\
\text { Perimeters }\end{array}$ & $\begin{array}{c}\text { Infill } \\
\text { Angle } \\
(\mathrm{deg})\end{array}$ & $\begin{array}{c}\text { Sample } \\
\text { Thickness } \\
(\mathrm{mm})\end{array}$ \\
\hline 1 & 40 & 2 & 0 & 0.31 \\
2 & 40 & 2 & 0 & 0.28 \\
3 & 40 & 2 & 45 & 0.31 \\
4 & 40 & 2 & 45 & 0.27 \\
5 & 40 & 2 & 90 & 0.5 \\
6 & 40 & 2 & 90 & 0.38 \\
7 & 40 & 3 & 0 & 0.37 \\
8 & 40 & 3 & 45 & 0.29 \\
9 & 40 & 3 & 45 & 0.29 \\
10 & 40 & 3 & 90 & 0.46 \\
11 & 40 & 3 & 90 & 0.49 \\
\hline
\end{tabular}




\begin{tabular}{l|llcl}
\hline 12 & 60 & 2 & 0 & 0.36 \\
13 & 60 & 2 & 45 & 0.34 \\
14 & 60 & 2 & 90 & 0.32 \\
15 & 60 & 2 & 90 & 0.33 \\
16 & 60 & 3 & 0 & 0.34 \\
17 & 60 & 3 & 45 & 0.34 \\
18 & 60 & 3 & 90 & 0.35 \\
\hline
\end{tabular}

Upon printing, specimens were speckle patterned with black paint and allowed to dry for at least 10 minutes, Figure 2c. Each sample is loaded into a Shimadzu EZ-Test material testing apparatus, Figure $2 \mathrm{~b}$, that is equipped with a $500 \mathrm{~N}$ load cell. The crosshead rate (rate of grip seperation) during tensile testing was $0.5 \mathrm{~mm} / \mathrm{min}$, during which high resolution images were acquired at a rate of 1 image per 6 seconds using a Nikon D3200. Standards for this test adhere to ASTM D882-10 except for a few notable exceptions. Crosshead rate was lower than typical standards due to low image capture rate capability. Initial grip separation was under the $250 \mathrm{~mm}$ specified for Young's Modulus evaluation because of bed construction area limitations.
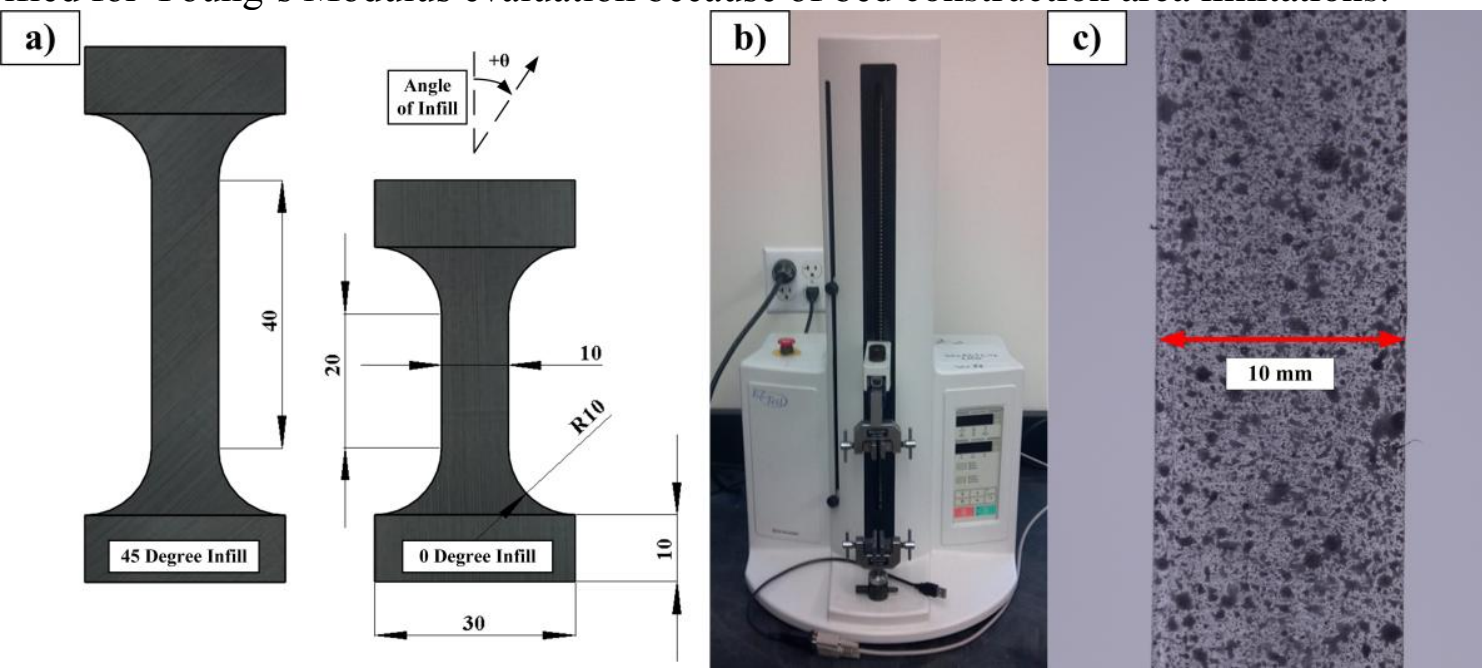

Figure 2. a) Schematic of dog bone 3D printed PVDF samples, b) Shimadzu EZ-Test, and c) sample speckle pattern.

For each specimen, the effective mechanical properties of the printed PVDF films were found in two ways. In the loading direction, the average normal stress within the gage area was assumed to be $\sigma_{\text {avg }}=F_{\text {load }} / A_{c s}$ where $F_{\text {load }}$ was the force value reported from the load cell and $A_{C S}$ was the cross sectional area of the sample. Strain in the loading direction was estimated using crosshead displacement and assuming that deformation occurred only in the gage region. From the slope of the stress-strain curve the Young's Modulus was estimated.

In addition, a 2D digital image correlation (DIC) analysis performed on the images of the deformed specimens was used to more accurately compute both axial and transverse strains. Speckle pattern images were loaded into a 2D-DIC software package to compute the in-plane strains $\left(\varepsilon_{\mathrm{xx}}, \varepsilon_{\mathrm{yy}}, \varepsilon_{\mathrm{xy}}\right)$ throughout the linear elastic loading regime. From these strains Young's Modulus and Poisson's ratio were evaluated.

It should be noted that the material properties found herein are the effective mechanical response of the printed PVDF film components. The directionality of the infill angle was 
expected to greatly influence the measured stiffness and yield stress. In addition, the crosssectional area was assumed to be a uniform rectangular section, when in reality there exists a small degree of irregularity in the geometry due to the printing process. Overhead microscope images for a 0 and 45 degree infill untested sample are shown in Figure 3 below.

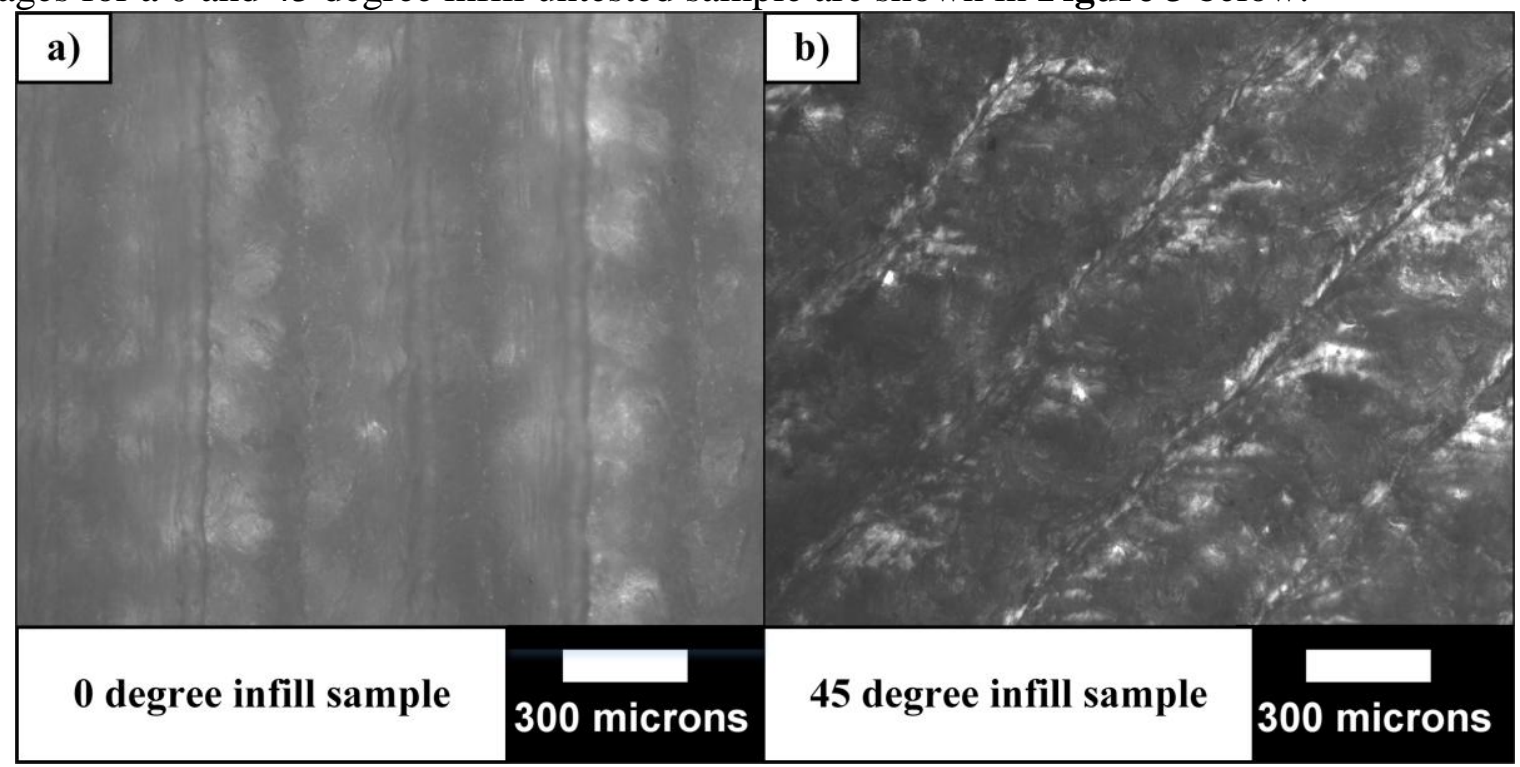

Figure 3. Overhead Microscope images of a a) 0 and b) 45 degree infill untested sample.

\subsection{Processing Parameter Effects}

Since PVDF's piezoelectric response is primarily dependent on the amount of crystalline $\beta$-phase in the films [21] [19], it is important to determine the $\beta$-phase constituents as a function of chosen process parameters. The key desired outcome is primarily a well-bonded layer with appreciable $\beta$-phase; a secondary goal is to have the dipoles aligned right after 3D printing. Parameters investigated include extrusion temperature, bed material, nozzle geometry, horizontal extrusion speeds, extrusion material multiplier, and extrusion direction effects. As stated above, the nozzle geometry should affect the immediately extruded plastic and the PVDF around it by allowing for a larger field area across the polymer over a longer period of relative time. For this reason the flat nozzle was chosen as the default constant in the initial parameter effect evaluation experiments. The extrusion multiplier (EM), or the modified amount of plastic being forced through the nozzle given a constant speed and deposition height, was also investigated. Results from previous studies suggest the higher the pressure on the extruded PVDF, the more crystalline [22] [23], and possibly higher concentration of $\beta$-phase [24] in the PVDF films.

Another effect that will be analyzed is the extrusion direction. Typical slicing profiles render a zigzag fill as shown in Figure 4a. There is a possibility that a one-way extrusion, Figure $4 b$, might give a better response due to aligned dipoles (longitudinal) being in the same direction for each line laid down. The first test was to see if it effects the amount of $\beta$-phase in the filament.

Samples printed for the purpose of testing piezoelectric properties was initially performed using 1x1" swatches, Figure 4c. They are $\sim 0.2 \mathrm{~mm}$ thick and are always printed on an undisturbed part of the bed that has an adhesion promoter spray. After each sample is fabricated, it is cleaned using acetone, 2-propynol and DI water to remove the adhesion promoter, then dried 
using an air gun. Table 3 shows initial experiments to determine the effects of FFF processing parameters on the formation of $\beta$-phase in the PVDF samples.

Table 3. Initial parameter effect evaluation experiments.

Effect

\begin{tabular}{|c|c|c|}
\hline Effect & Variable Change & Constants \\
\hline Hot End Temperature & $\begin{array}{l}160^{\circ}-200^{\circ} \text {, by } 10^{\circ} \mathrm{C} \\
\text { increments }\end{array}$ & $\begin{array}{c}\text { Flat nozzle, Kapton coated bed } \\
\text { at } 100^{\circ} \mathrm{C}, 1 \times \mathrm{EM}, \\
10 \mathrm{~mm} / \mathrm{s}, \text { poled } 1,750 \mathrm{~V} \\
\end{array}$ \\
\hline Bed Material & $\begin{array}{l}\text { Kapton at } 100^{\circ} \mathrm{C} \text { and } 3 \mathrm{M} \\
\text { tape at room temp. Poled } \\
\text { and unpoled }\end{array}$ & $\begin{array}{c}\text { Flat nozzle, Hot End at } 200^{\circ} \mathrm{C}, \\
1 \mathrm{x} \mathrm{EM}, 10 \mathrm{~mm} / \mathrm{s}\end{array}$ \\
\hline Nozzle Type & $\begin{array}{c}\text { Sharp versus flat brass } \\
\text { nozzle, poled and } \\
\text { unpoled }\end{array}$ & $\begin{array}{c}\text { Kapton coated bed at } 100^{\circ} \mathrm{C} \\
\text { Hot End at } 200^{\circ} \mathrm{C}, 1 \times \mathrm{EM} \\
\text { poled } 1,750 \mathrm{~V}\end{array}$ \\
\hline Horizontal Extrusion Speed & $3,10,20,30,40,50 \mathrm{~mm} / \mathrm{s}$ & $\begin{array}{l}\text { Flat Nozzle, Kapton coated } \\
\text { bed at } 100^{\circ} \mathrm{C} \text {, Hot End at } \\
200^{\circ} \mathrm{C}, 1 \times \mathrm{EM} \text {, poled } 1,750 \mathrm{~V}\end{array}$ \\
\hline Extrusion Multiplier & $0.75,1,1.25,1.5 \mathrm{x}$ & $\begin{array}{l}\text { Flat nozzle, Kapton coated bed } \\
\text { at } 100^{\circ} \mathrm{C} \text {, Hot End at } 200^{\circ} \mathrm{C}, \\
10 \mathrm{~mm} / \mathrm{s} \text {, poled at } 1,750 \mathrm{~V}\end{array}$ \\
\hline $\begin{array}{l}\text { Zigzag vs One-Way- } \\
\text { Extrusion }\end{array}$ & $\begin{array}{l}\text { Rectilinear fill versus } \\
\text { extruding one direction } \\
\text { constantly, poled and } \\
\text { unpoled }\end{array}$ & $\begin{array}{l}\text { Flat nozzle, Kapton coated bed } \\
\text { at } 100^{\circ} \mathrm{C}, 1 \mathrm{x} \mathrm{EM} \text {, Hot End at } \\
\qquad 200^{\circ} \mathrm{C}, 10 \mathrm{~mm} / \mathrm{s}\end{array}$ \\
\hline
\end{tabular}

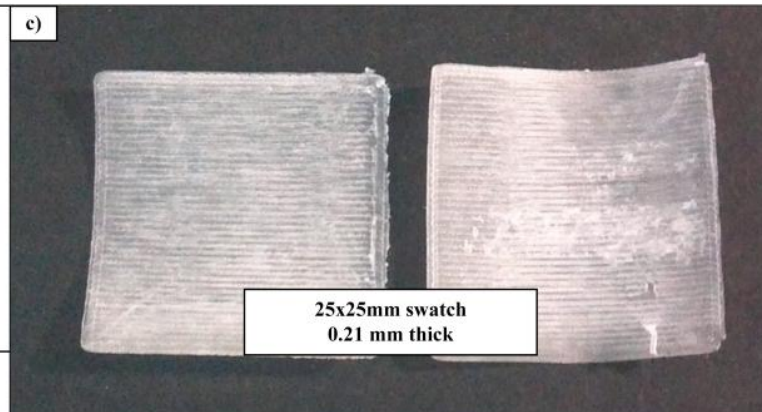

c)

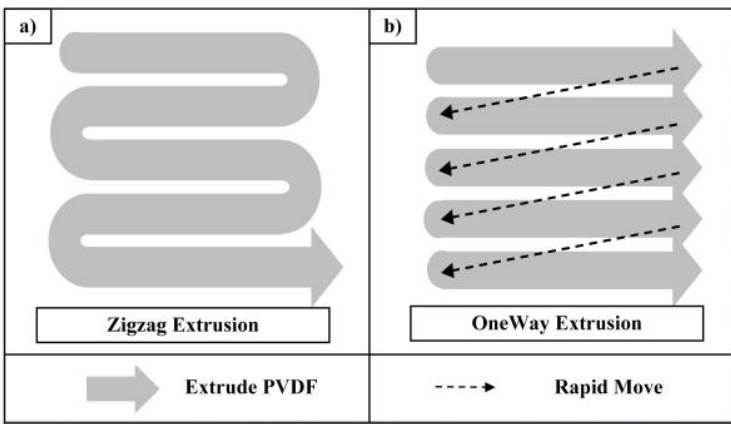

$100 \times 25 \mathrm{~mm}$ swatch $0.22 \mathrm{~mm}$ thick d)

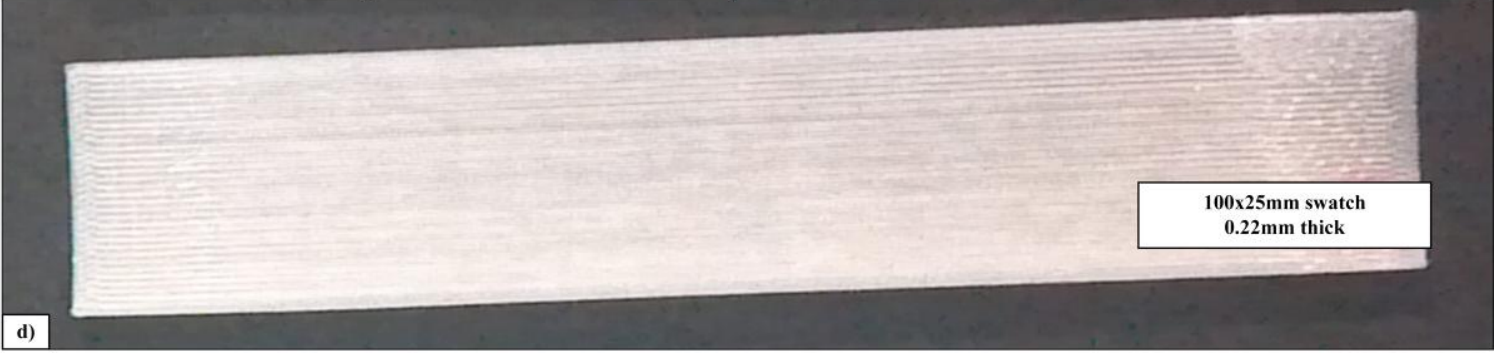


Figure 4. Extrusion method variations tested, including a) zigzag and b) one-way print routines, c) $25 \times 25 \mathrm{~mm}$ and d) $100 \times 25 \mathrm{~mm}$ film swatch specimen sizes.

Once a set of processing parameters lent satisfactory films, samples were fabricated and aluminum electrodes were sputtered/applied for piezoelectric performance characterization. Satisfactory will have a respectable $\beta$-phase, smooth surfaces on the top and bottom, and have minimal porosity so the electrodes do not short. Porosity in this case refers to gaps between PVDF extruded polymer paths or accidental breaks due to poor plastic adhesion.

Along with the 3D printed specimens, reference samples were also prepared from baseline materials (manufacturer's PVDF resin pellets, the extruded filament, etc.) to determine the influence of the 3D processing parameters on PVDF microstructure. These reference samples include the raw PVDF resin pellets, the extruded $1.75 \mathrm{~mm}$ filament processed at $220^{\circ} \mathrm{C}$, strained pellets/filaments, and strained and corona poled extruded strips. Images of the baseline material are shown in Figure 5a. A simple vice was used to crush the resin and filament so that it underwent a highly strained process.

In addition to the baseline tests, select 3D printed films were also post-processed using mechanical stretching while under an electrical field. Swatches were cut to size so that they could be strained and corona poled, Figure 5b. Corona poling required a heated bed at about $80^{\circ}$ $\mathrm{C}$, a pulling rod to strain the material, and a steel needle at $7.8 \mathrm{kV}$ placed $10 \mathrm{~mm}$ above the sample, Figure 5c. As the material is strained under high electric field, some of the $\alpha$ crystalline phases convert to $\beta$-phase while $\beta$-phase dipoles are induced to align with the applied electric field at the same time. Poled and processed samples are shown in Figure 5d.

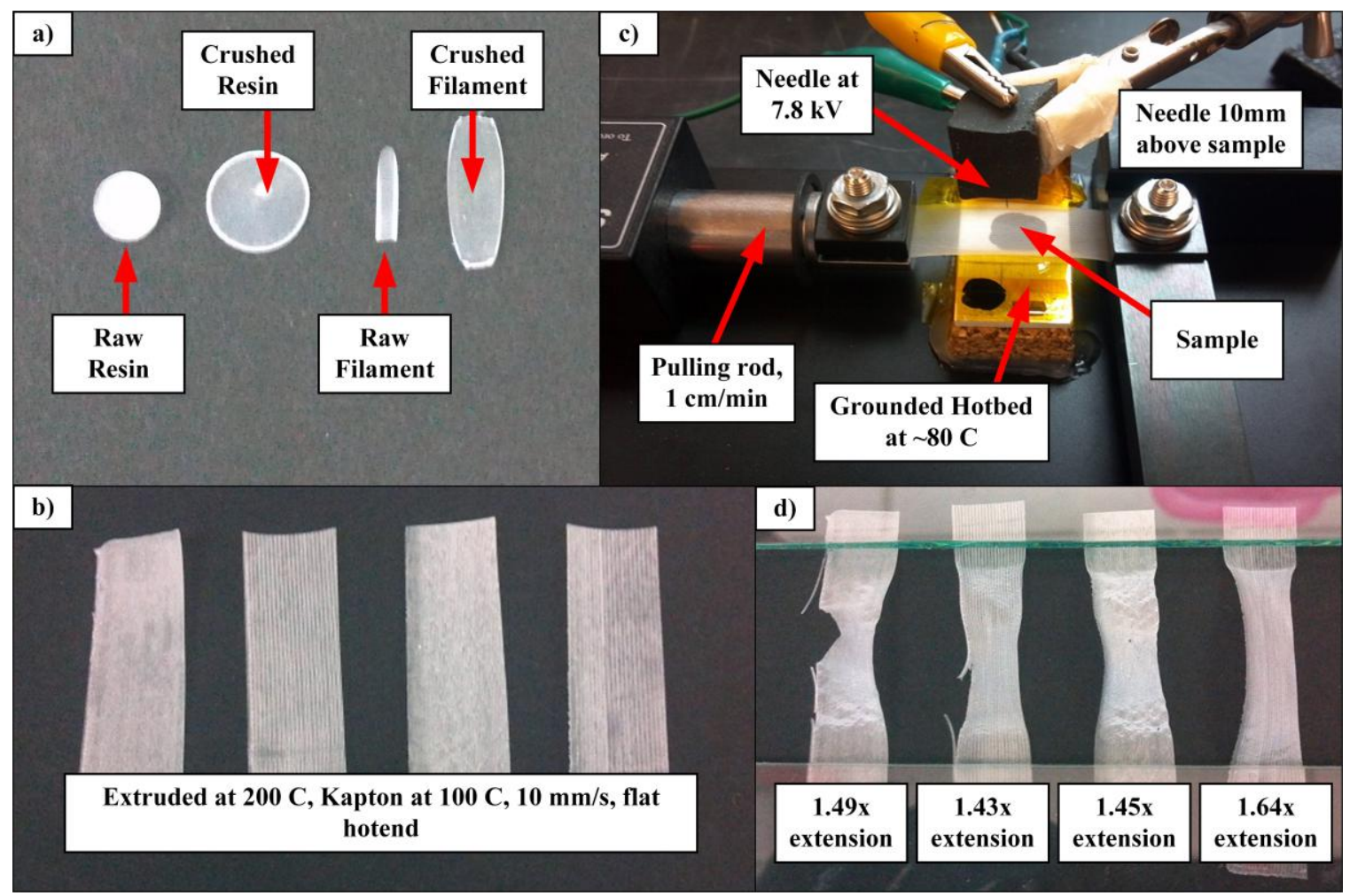

Figure 5. a) PVDF reference samples, b) test swatches before poling, c) corona stretch and pole station, and d) swatches after stretch and poling. 


\subsection{Piezoelectric Properties}

To estimate the piezoelectric coefficients of selected samples, unimorph specimens are constructed using PVDF as the top active layer and steel shim stock as the passive bottom layer, with an adhesive in-between. The equations determining the small static deflection of a unimorph (neglecting the adhesive layer stiffness) are derived using the method from [21]. A schematic of the beam is shown in Figure 6a. For a fixed width $w$ and knowing that the post deflection must be in static equilibrium, the sum of the forces and moments must equal zero

$$
\begin{gathered}
F_{x}=w \int_{z 0}^{z i} \sigma_{x}(z) d z \\
M_{o}=w \int_{z 0}^{z i} \sigma_{x}(z) z d z
\end{gathered}
$$

where $\sigma_{x}(z)$ is the $\mathrm{x}$ stress profile through the height of the beam. The stress profile for the piezoelectric and substrate layer are

$$
\begin{gathered}
\sigma_{p}=E_{p}\left(\varepsilon_{0} z-d_{31} \frac{V}{h_{p}}\right) \\
\sigma_{s}=E_{s}\left(\varepsilon_{0} z\right)
\end{gathered}
$$

where $\varepsilon_{0}$ is the strain slope for the unimorph, $E_{p}$ and $E_{s}$ are the Young's modulus for the piezoelectric and substrate layer respectively, $d_{31}$ is the piezoelectric strain coefficient, $V$ is the voltage applied to the piezoelectric layer, and $h_{p}$ is the thickness of the piezoelectric layer. The equation for deflection as a function of position along a unimorph beam length is

$$
\delta(x)=\frac{3 E_{p} d_{31} V E_{s} h_{s}\left(h_{p}+h_{s}\right)}{E_{P}^{2} h_{p}^{4}+4 E_{p} E_{s} h_{p}^{3} h_{s}+6 E_{p} E_{s} h_{p}^{2} h_{s}^{2}+4 E_{p} E_{s} h_{p} h_{s}^{3}+E_{s}^{2} h_{s}^{4}} x^{2}
$$

where $h_{s}$ is the height of the substrate layer and $x$ is the position of the horizontal part of the unimorph. This method of constructing a relation between $d_{31}$ coefficient and static displacement will be used to evaluate piezoelectric coefficients.

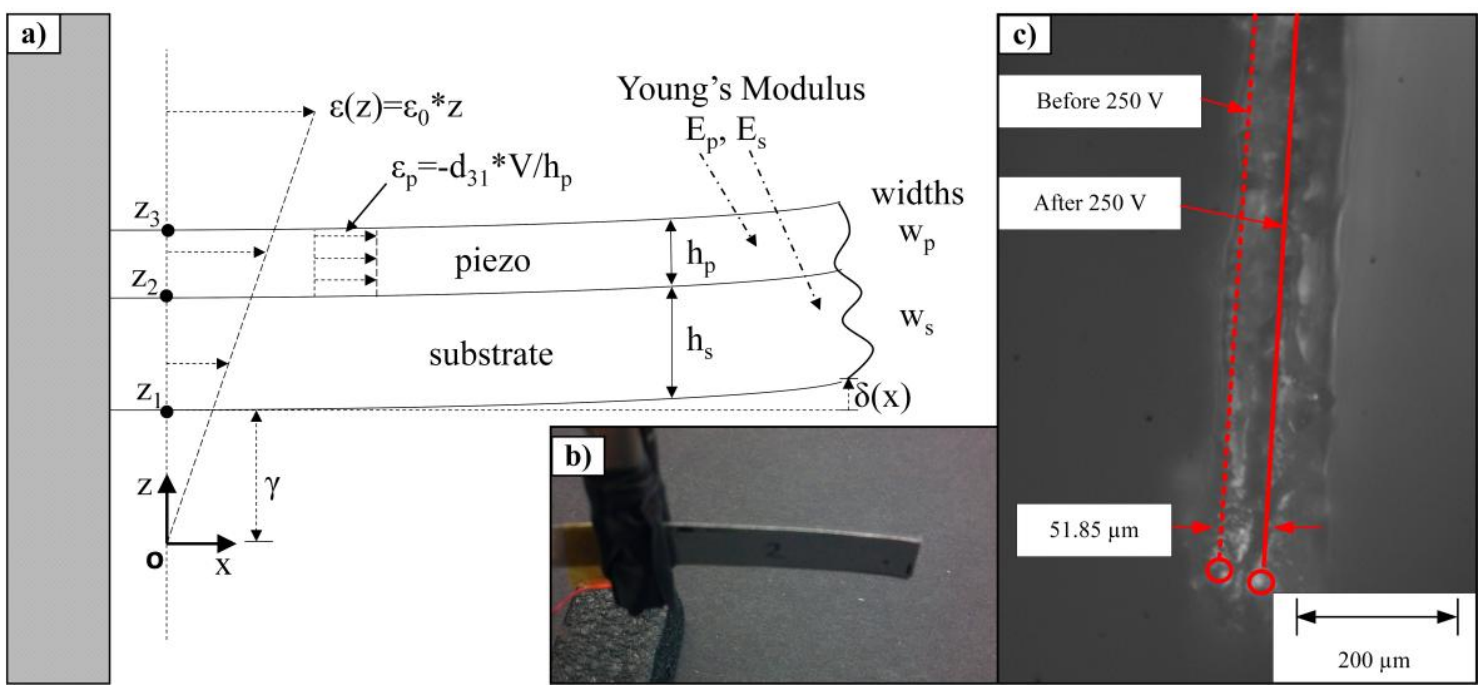

Figure 6. a) Schematic of unimorph beam, b) image of commercial test beam, c) 20x microscope image showing post voltage deflection. 


\section{Results}

\subsection{Young's Modulus and Poisson's Ratio}

The stress versus strain curves derived from the Shimadzu material testing machine are shown in Figure 7 for each infill angle. Engineering strain was calculated in the linear region for every sample via the Shimadzu load cell/displacement method and the 2D DIC method. From these values Young's Modulus is evaluated. Poisson's ratio is derived using the 2D DIC method only.
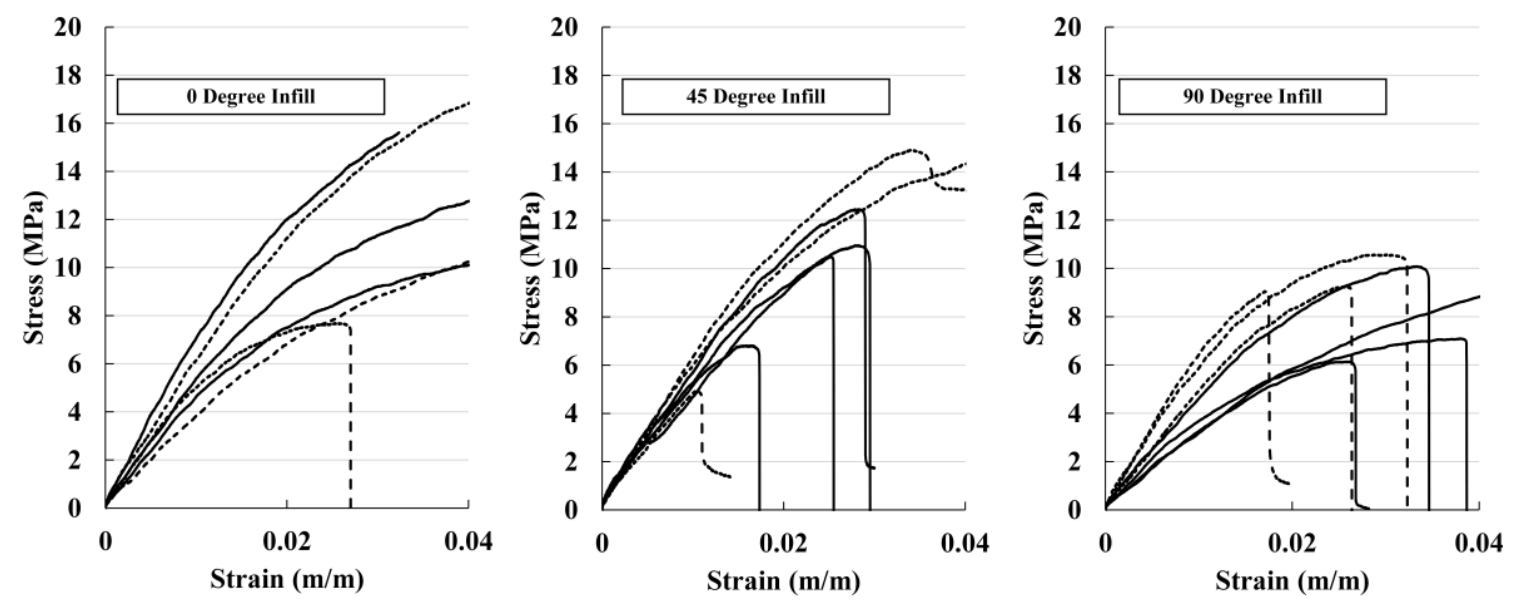

Figure 7. Stress-strain graphs derived from Shimadzu machine for various infill dog bone PVDF structures. Solid lines represent $40 \mathrm{~mm}$ specimens, while dashed lines are $60 \mathrm{~mm}$.

From Figure 7 ultimate stress is, on average, lowest in the 90 degree infill samples, though the 0 and 90 degree infill have about the same stiffness response. Results from the DIC package analysis are shown in Figure 8 for a 0 degree angle sample. The sample is under $6.1 \mathrm{~N}$ of tensile load (about 1.7 MPa of stress). 


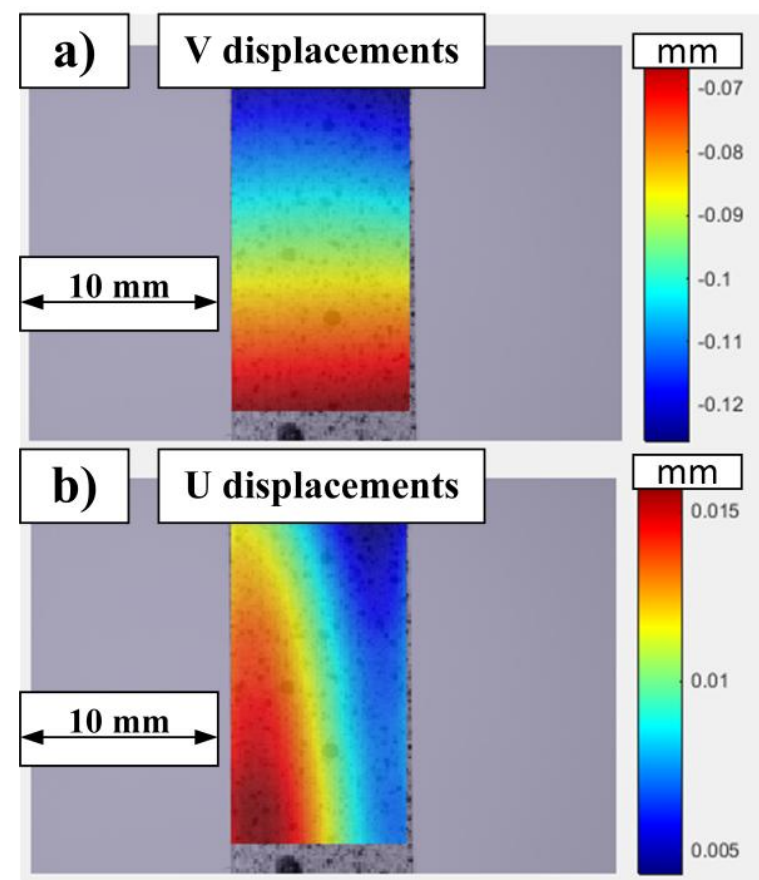

Figure 8. 2D DIC results for tensile testing of a 0 degree angle under $6.1 \mathrm{~N}$ of force. Results for a) $v$ (vertical) displacements, b) $u$ (horizontal) displacements.

Table 4 shows the calculated Young's Modulus and Poisson's ratio for the three tested infill angles. The number of 3D printed perimeters did not seem to have a trending effect on any of the mechanical properties. The length of samples had an effect as the infill angle went from 0 to 90 degrees as shown by Figure 7. Measured Young's Modulus values for single layer test strips are lower than reported from literature: $3 \mathrm{GPa}$ [25], $2.8 \mathrm{GPa}$ [26], $2.5 \mathrm{GPa}$ [27], and 1.7 $\mathrm{GPa}$ from Kynar 740 datasheet. It should be noted that the Kynar 740 bulk Modulus of Elasticity was measured at $1 \mathrm{~mm} / \mathrm{min}$ which is twice the crosshead rate of our test specimens. Another important fact the reader should be cognitive of is that the number of samples tested in this research is below that which are needed to make these results statistically viable.

Table 4. Shimadzu and DIC results for Young's Modulus and Poisson's ratio for all dog bone

\begin{tabular}{|c|c|c|c|c|c|c|}
\hline $\begin{array}{l}\text { Infill } \\
\text { Angle } \\
\text { (deg) }\end{array}$ & $\begin{array}{c}\mathrm{E}_{\text {Shimadzu }} \\
(\mathrm{MPa}), \\
\text { Average }\end{array}$ & $\begin{array}{l}\text { st } \\
\mathrm{E}_{\text {Shimadzu }} \\
(\mathrm{MPa}), \\
\text { Standard } \\
\text { Deviation }\end{array}$ & $\begin{array}{c}\mathrm{E}_{\mathrm{DIC}} \\
(\mathrm{MPa}), \\
\text { Average }\end{array}$ & $\begin{array}{c}\mathrm{E}_{\mathrm{DIC}} \\
(\mathrm{MPa}), \\
\text { Standard } \\
\text { Deviation }\end{array}$ & $\begin{array}{c}v_{\text {DIC }} \\
\text { Average }\end{array}$ & $\begin{array}{c}v_{\text {DIC }}, \\
\text { Standard } \\
\text { Deviation }\end{array}$ \\
\hline 0 & 484 & 50 & 497 & 41 & 0.243 & 0.064 \\
\hline 45 & 481 & 78 & 545 & 165 & 0.361 & 0.060 \\
\hline 90 & 419 & 100 & 429 & 84 & 0.310 & 0.063 \\
\hline All & 457 & & 486 & & 0.305 & 0.062 \\
\hline
\end{tabular}

Void spaces in the PVDF samples are ideally near zero due to specimen width calculations done during slicing. This is not realistically accomplished as the heights of each sample are shown to vary from Table 2 above. Extrudate cross sectional area for the chosen slicing algorithm are described as a rectangle with rounded edges 


$$
\text { Area }_{\text {extrudate }}=(W-H) H+\pi\left(\frac{H}{2}\right)^{2}
$$

where $W$ and $H$ are the width and height of the extrudate with void spacing being

$$
\text { Area }_{\text {void }}=H^{2}+\pi\left(\frac{H}{2}\right)^{2}
$$

assuming that each of the extrudate areas are just touching. As the void area goes to zero then the spacing of extrudate pathing is

$$
\text { Spacing }=W-\left(H-\frac{1}{4} \pi H\right)
$$

which would create $0 \%$ total voids by volume, or the ideal case.

Estimation of trapped voids is done by weighing three of each infill sample (0, 45, and $90^{\circ}$ ), spraying all sample with a light and extremely thin sealant (Scotchgard Heavy Duty Water Repellent(3M)), immersing them in water and recording the volume displaced. With the original mass, volume displaced, and knowing the density of the filament prior to deposition, the percent of locked void spacing can be evaluated. While this will not evaluate ' $v$ ' crevices (surface roughness effects), it will give an approximation of how much air is trapped in the samples which may affect mechanical and electrical properties. The results for trapped air void \% by volume is shown in Table 5 below.

Table 5. Trapped air void \% by volume

\begin{tabular}{c|c|c|c} 
Fill Angle & $\begin{array}{c}\text { Density } \\
\left(\mathrm{g} / \mathrm{cm}^{3}\right)\end{array}$ & $\begin{array}{c}\text { Filament Density } \\
\left(\mathrm{g} / \mathrm{cm}^{3}\right)\end{array}$ & Void \% \\
\hline 0 & $1.56 \pm 0.07$ & 1.78 & 12.36 \\
45 & $1.67 \pm 0.07$ & 1.78 & 6.18 \\
90 & $1.51 \pm 0.03$ & 1.78 & 15.17
\end{tabular}

\subsection{Printing Parameter Effects on $\beta$-Phase}

To estimate the relative amount of $\beta$-phase in each sample, Fourier transform infrared spectroscopy (FTIR) is performed using a Perkin Elmer Spectrum 100 FT-IR spectrometer. Since the samples are relatively thick, an attenuated total reflectance (ATR) attachment is needed to obtain viable spectra. This means that only a certain amount of material on the surface can be analyzed. The ATR depth of penetration is defined as

$$
p=\frac{\lambda}{2 \pi \sqrt{(\sin \theta)^{2}-\left(\frac{n_{2}}{n_{1}}\right)^{2}}}
$$

where $\lambda$ is the wavelength of light in the $\mathrm{ZnSe}$ crystal, $\theta$ here is the incident angle of light entering the sample (typically 45 degrees), $n_{1}$ is the index of refraction of the ZnSe crystal (2.4), and $n_{2}$ is the index of refraction of PVDF (about 1.4) [28].

In order to compare results of FTIR spectra, the scanned data had to be normalized because the peaks detected are a function of the amount of material in contact with the ATR crystal. To account for variability in contact area, a common peak in the samples spectra was identified so that each spectra could be normalized to it. The peak at $1070 \mathrm{~cm}^{-1}$ was deemed consistent in amplitude so all other spectra were normalized to that peak. As it turns out, 1070 $\mathrm{cm}^{-1}$ is independent of the three primary phases found in PVDF and has a linear relationship with the thickness of the sample in normal FTIR [29]. Since measurements are done using an ATR 
adapter, the depth of absorption at that wavenumber is constant, thus why it was observed that $1070 \mathrm{~cm}^{-1}$ always had the same relative amplitude.

In Figure 9 the raw and crushed Kynar 740 resin, raw and crushed extruded filament, the corona poled samples of Figure 5, and a 3D printed high $\beta$-phase containing sample from the initial parameter investigations are shown. Mechanically crushing the resin and filament in a vice increased $\beta$-phase $\left(840 \mathrm{~cm}^{-1}\right)$ as expected when inducing high strains into the material. Figure 9 also shows that as soon as the resin is thermally processed (via a filament extruder) the amount of $\alpha$-phase increased greatly in the material $\left(760,796,974 \mathrm{~cm}^{-1}\right)$. Wavenumbers identifying PVDF phases come from the Spectrum 100 software as well as [30], [31], [32].

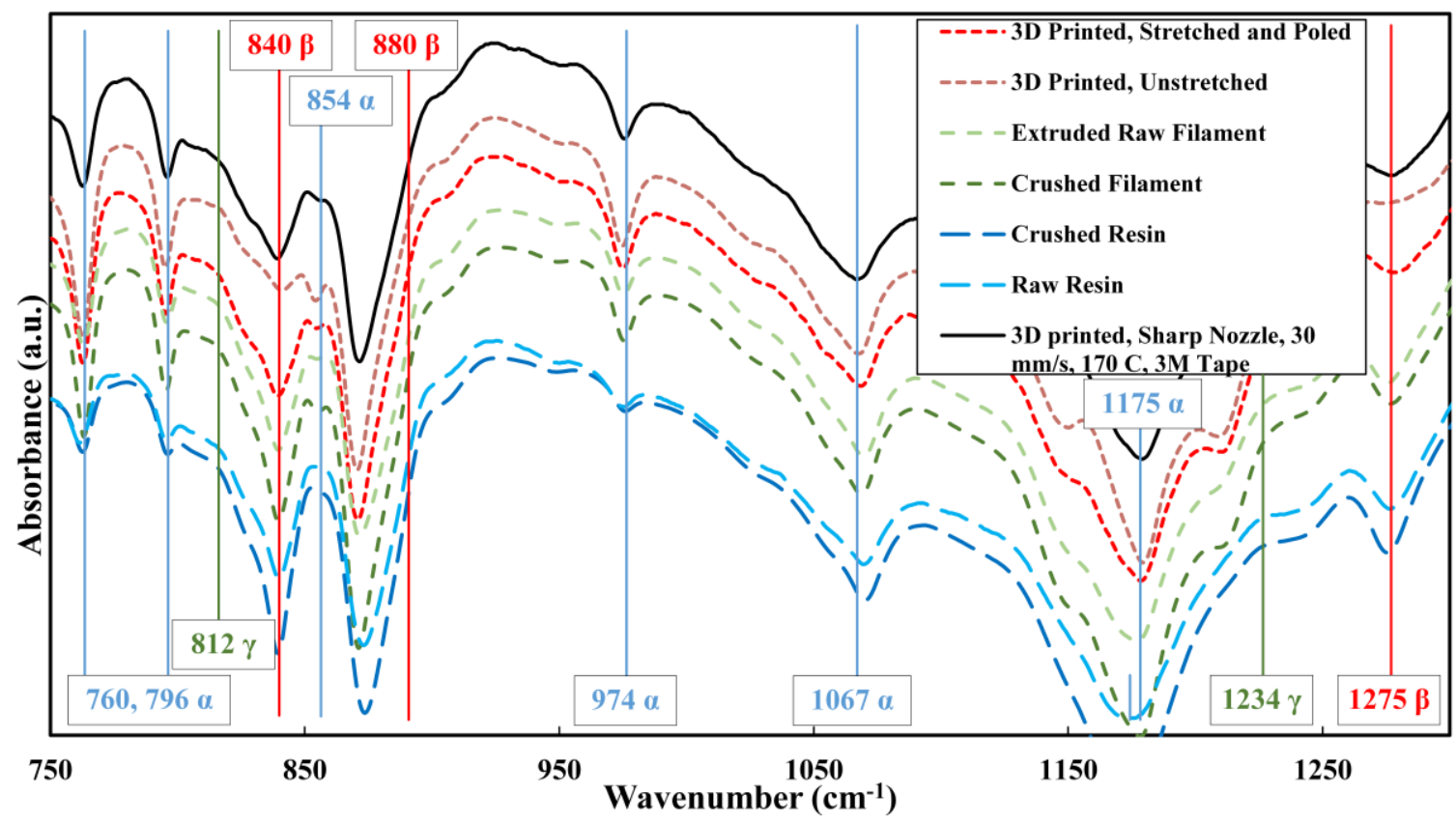

Figure 9. FTIR-ATR normalized results showing absorbance peaks for raw and crushed resin and filament. Includes the unstretched and stretched corona poled samples. Also added in is a high $\beta$-phase content sample from the initial experiments.

Effects such as bed material, print speed, and temperature appeared to have an effect on the amount of $\beta$-phase in the samples. Conversely, zigzag, nozzle type, and extrusion multiplier did not produce any observable trends within the initial experiments. Bed material and in-situ poling were also found to have a small effect on the amount of $\beta$-phase in the samples, as shown in Figure 10. The Kapton \#1 sample had 1,750 volts applied to the hot end while Kapton \#2 did not. There was a subtle increase in the amount of $\beta$-phase for the poled sample. $3 \mathrm{M}$ sample \#1 (blue painters tape) had 1,000 volts on the hot end and the $3 \mathrm{M}$ sample $\# 2$ did not. $\beta$-phase content seemed to be the same for the poled and unpoled $3 \mathrm{M}$ samples. The most significant finding here was that $3 \mathrm{M}$ tape gave more $\beta$-phase than the Kapton tape, even when poled at a lower electric fields. 


\section{Bed Material Effect}
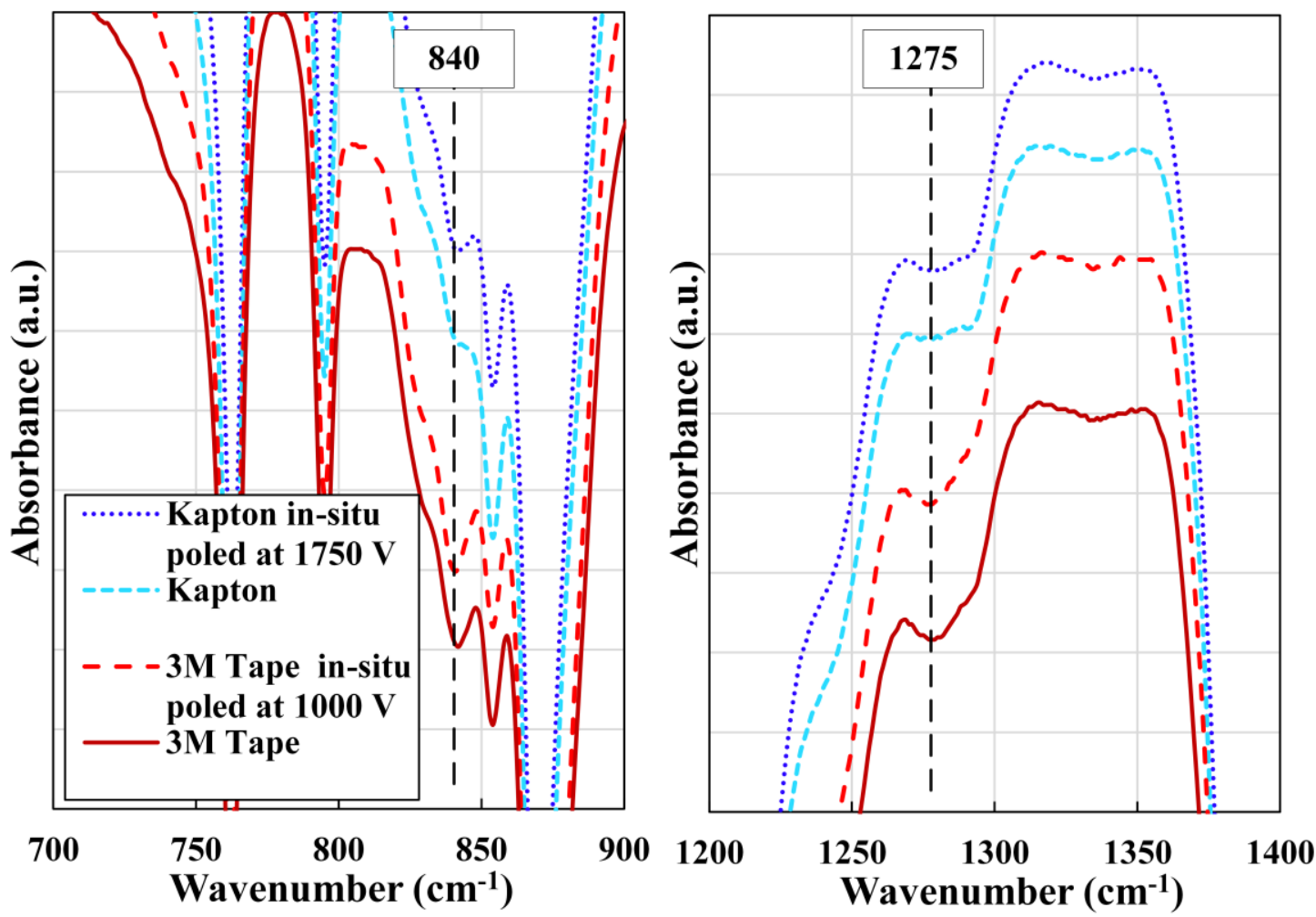

Figure 10. The effect of bed material on the amount of PVDF $\beta$-phase.

Horizontal extrusion speed effects are shown in Figure 11. Faster extrusion speeds produce more $\beta$-phase than slower speeds. This has the tradeoff of decreased poling time for increased printing speeds, which may also affect dipole alignment for samples coming off of the build bed. Faster printing speeds also increase fluid pressure within the nozzle. 
Speed Effect
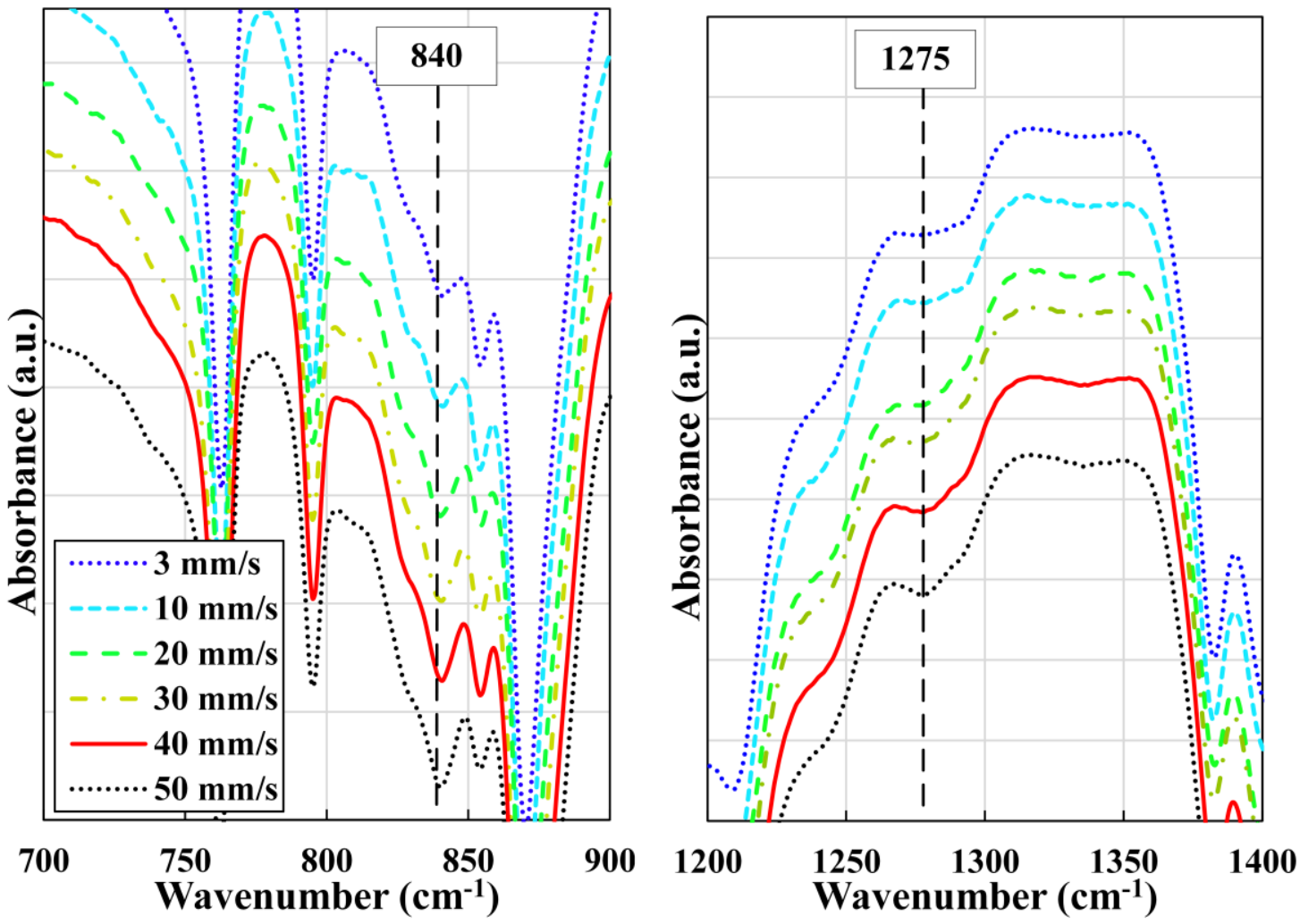

Figure 11. The effect of speed on the amount of PVDF $\beta$-phase using the flat nozzle and Kapton tape.

Hot end temperature influence on $\beta$-phase is shown in Figure 12. Given the constants of the experiment, colder extrusions produce higher $\beta$-phase in the PVDF. Adhesion to the bed, and adhesions to the PVDF itself is lowered significantly though. Below $190^{\circ} \mathrm{C}$ the samples are so simple to pull apart that further experimentation below this temperature was abandoned. 
Temperature Effect
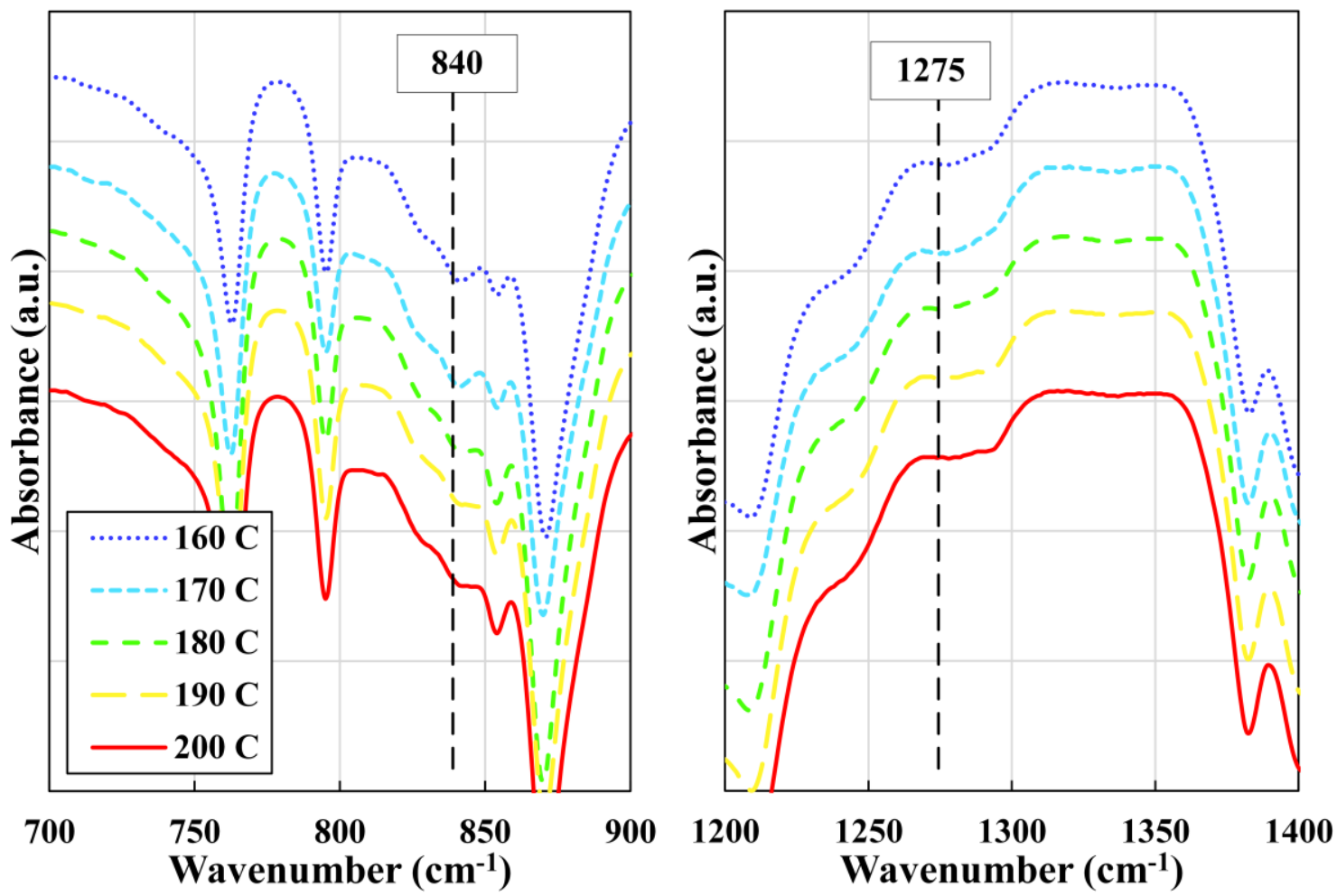

Figure 12. The effect of extrusion temperature on the amount of PVDF $\beta$-phase.

The first round of parameter investigations showed that higher temperatures were required for good adhesion, that faster extrusion speeds on $3 \mathrm{M}$ tape increased $\beta$-phase, and that applied voltage potentially increased $\beta$-phase. A sharp nozzle also made smoother surfaces than the alternate flat tip and is a mandatory characteristic for applying electrodes. A second round of experiments were performed to test in-situ poling voltage and the processes effect on $\beta$-phase using the previous knowledge obtained. Samples at $30 \mathrm{~mm} / \mathrm{s}$, with a $3 \mathrm{M}$ tape bed, and a sharp nozzle are printed at different temperatures with and without nozzle voltage. Figure 13 below shows that an electric field applied to the PVDF does indeed enhance the amount of $\beta$-phase but only at increased temperatures.

Thus, samples printed at a speed of $30 \mathrm{~mm} / \mathrm{s}, 3 \mathrm{M}$ tape as the adhesion material, a sharp nozzle at the higher temperature, and an applied voltage of $1000 \mathrm{~V}$ were evaluated for a piezoelectric response. Although the majority of experiments are performed with a flat nozzle the sharp nozzle extruder geometry was selected in the end as it produced the smoothest specimen surfaces, which was a consideration for electrode deposition. 


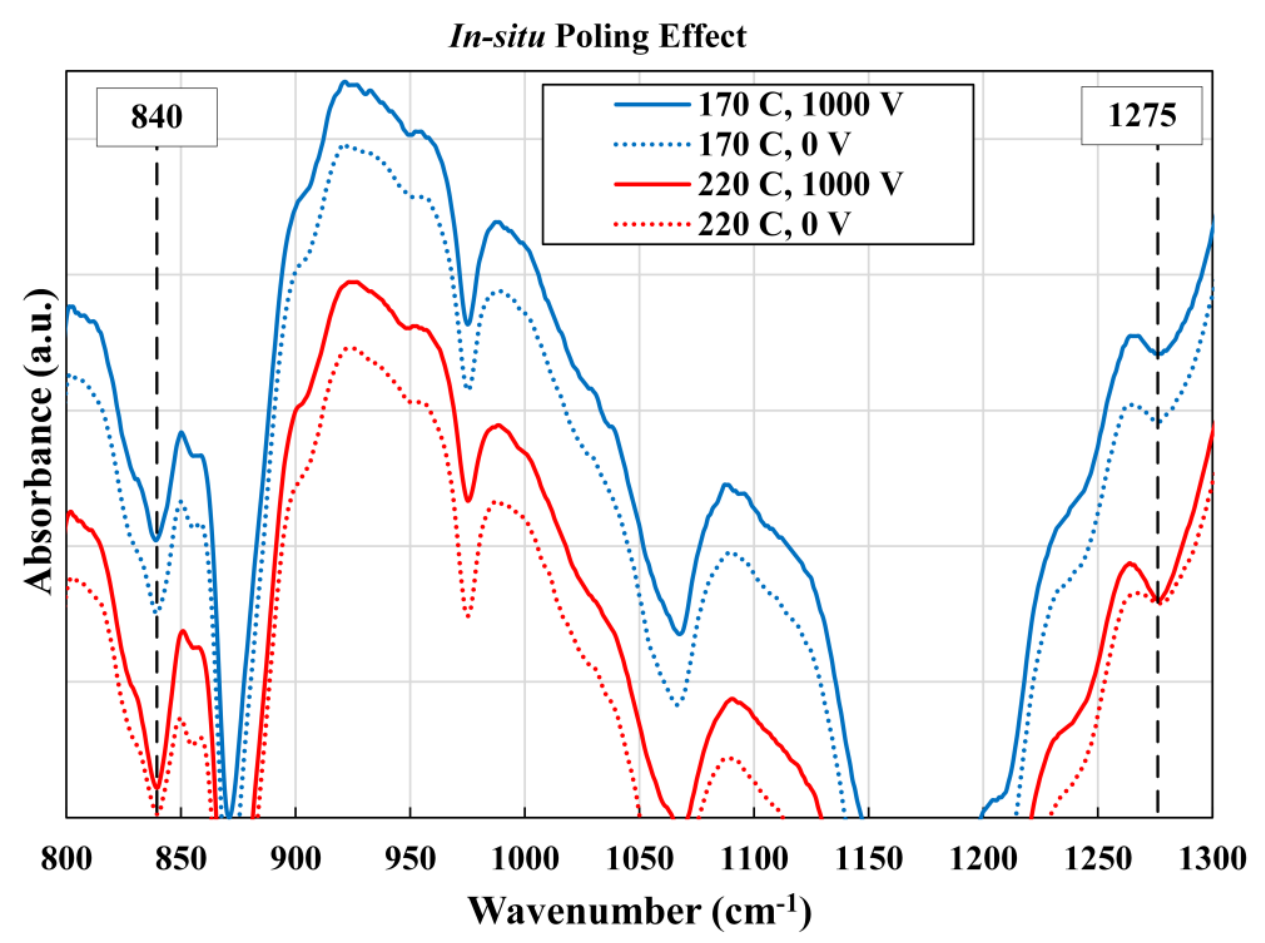

Figure 13. In-situ voltage effects on the amount of PVDF $\beta$-phase.

Horizontal extrusion speed effects on the surface morphology (top side) of PVDF printed samples is shown in Figure 14 below. These samples correspond to the FTIR-ATR results from Figure 11 above. A general transition of surface morphology can be observed as the printing speed varies.

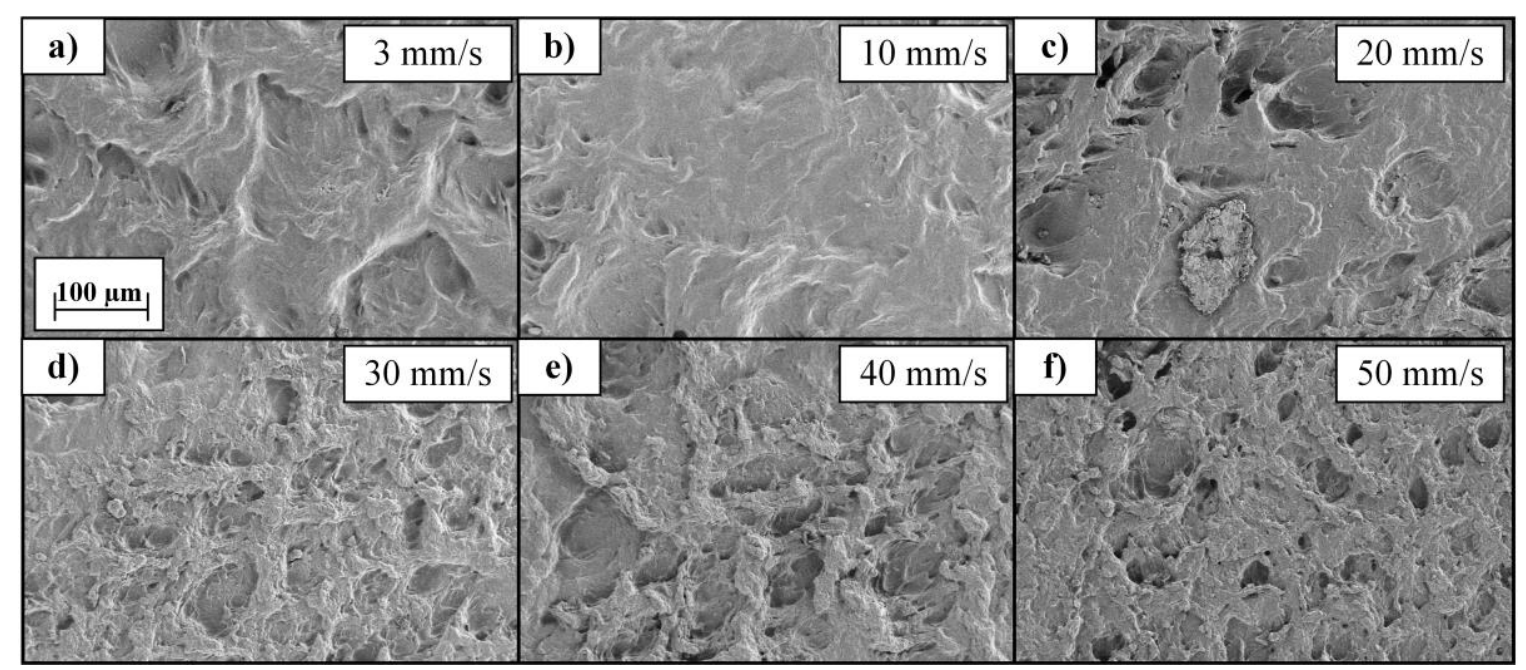

Figure 14. SEM images of the top surfaces corresponding to a) $3 \mathrm{~mm} / \mathrm{s}$, b) $10 \mathrm{~mm} / \mathrm{s}$, c) 20 $\mathrm{mm} / \mathrm{s}$, d) $30 \mathrm{~mm} / \mathrm{s}$, e) $40 \mathrm{~mm} / \mathrm{s}$, f) $50 \mathrm{~mm} / \mathrm{s}$ feed rates.

\subsection{Piezoelectric Coefficient Evaluation}

To verify the piezoelectric response testing methodology, the piezoelectric coefficient for a commercially produced piezoelectric PVDF sheet was first evaluated. PVDF strips from 
Goodfellow (FV301960/3, uniaxially strained, $\mathrm{d}_{31}=19 \mathrm{pC} \mathrm{N}^{-1}, \mathrm{~d}_{33}=-20 \mathrm{pC} \mathrm{N} \mathrm{N}^{-1}, 110 \mu \mathrm{m}$ thick) were adhered to a steel shim stock (50 $\mu \mathrm{m}$ thick) using a thin industrial adhesive. As received, the commercial strips are sputtered with a $2 \mathrm{ohms} / \mathrm{square}$ film of aluminum as electrodes. The bilayer beam was clamped on one end, giving an effective length of $28 \mathrm{~mm}$, with a width of 6.5 $\mathrm{mm}$. Prior to piezo-response testing, the mechanical stiffness of the Goodfellow PVDF was also experimentally determined via tensile testing, giving an average Young's Modulus of 0.928 GPa.

During piezoelectric response testing, a voltage differential is applied across the active piezoelectric layer, inducing a deflection of the composite structure as described by $\mathrm{Eq} 5$. Voltage differentials of $250 \mathrm{~V}$ and $500 \mathrm{~V}$ were applied to the unimorph beam while the tip deflection was recorded under an optical microscope. Images of the tip displacement were taken for multiple tests and used to compute the transverse piezoelectric coefficient, $\mathrm{d}_{31}$. Based on these experiments, the $\mathrm{d}_{31}$ coefficient of the commercial PVDF was $19.4 \mathrm{pC} \mathrm{N}^{-1}$, which is $2.1 \%$ higher than the manufacture specifications.

For the 3D printed PVDF strips fabricated in this work, three different types of electrodes were considered: physical vapor deposited aluminum, CircuitWorks CW2400 conductive epoxy, and Anders Product Wire Glue. The CircuitWorks epoxy adhered well but eventually became brittle and cracked even when the thinnest layers were applied. Sputter coated aluminum electrodes $(300 \mathrm{~nm})$ adhered well, but only when immediately preceded by a surface plasma treatment. An adhesion assisting plasma clean was done in $8 \mathrm{sccm}$ nitrogen with an RF power source at $50 \mathrm{~W}$ for 2 minutes. Physical vapor deposition parameters for the aluminum are $300 \mathrm{~W}$ and $5 \mathrm{mTorr}$. The biggest downside to the aluminum deposition method was that it tended to find even the smallest gaps in the film, resulting in electrical shorts to the other side of the film, thus decreasing useful PVDF area. The most effective electrode material was found to be the Anders Wire Glue, which utilizes carbon as the conducting material. When mixed with deionized water and put down in thin layers, it adhered extremely well to the PVDF surface when dry. The sheet resistance of the Wire Glue was the worst of the other two materials at 5001,000 ohm/square but since PVDF tends to have a high optimum resistance [33] for energy harvesting compared to other piezoelectric materials this was deemed acceptable for initial coefficient evaluations.

After electrode application, the 3D printed PVDF films were evaluated for an initial piezoelectric response. This evaluation was performed by connecting the electrodes to an open circuit through an oscilloscope and monitoring the induced voltage response during rapid deformation of the composite beam structure. If there were substantial dipole alignment within the specimens after printing, then the beam would generate a decaying voltage sine wave. However, regardless of the printing parameters, none of the "as-printed" films tested demonstrated a significant voltage response. Instead, a post-print poling procedure to induce dipole alignment was required to produce a piezoelectric response within the PVDF films.

Samples selected for post-print poling were printed at $200^{\circ} \mathrm{C}, 30 \mathrm{~mm} / \mathrm{s}, 1 \mathrm{x}$ extrusion multiplier, with a sharp nozzle at $1,000 \mathrm{~V}$, and a blue painters tape adhesion bed surface at room temperature, as these parameters were demonstrated to give higher $\beta$-phase content, good interlayer adhesion, and low surface roughness.

To avoid shorting during contact poling, two 3D printed PVDF strips $(0.3 \mathrm{~mm}$ thick $)$ were adhered back-to-back with JB Weld and allowed to dry. The laminate was cut $13.8 \mathrm{~mm}$ wide by $100 \mathrm{~mm}$ long. Carbon electrodes were applied to the top and bottom, keeping about a $1 \mathrm{~mm}$ gap from the edges to prevent short arcing paths about the thickness. Conductive copper 
tape connection tabs were put down near the end of the device for external connections. Then a steel shim (50 $\mu \mathrm{m}$ thick) was adhered using JB Weld to one side, making a unimorph.

During poling the unimorph is put into a canola oil bath at $80^{\circ} \mathrm{C}$ while a voltage setting of $300 \mathrm{~V}$ was applied across the electrodes. After an hour, the voltage was ramped to $5 \mathrm{kV}$ and held for 1 hour. The temperature of the canola oil was then brought down to room temperature, thus aligning the dipoles under a $8.33 \mathrm{MV} / \mathrm{m}$ electric field.

Since contact poling is performed in canola oil at $80^{\circ} \mathrm{C}$, it is important to understand how JB Weld's stiffness is modified given the different conditions. Three strips of JB Weld were cured, one in air for one day, another in a $100 \mathrm{C}$ oven for 1 hour, and lastly in canola oil at $80 \mathrm{C}$ for 1 hour. Shimadzu tensile testing revealed a Young's modulus of $252 \mathrm{MPa}, 999 \mathrm{MPa}$, and 733 $\mathrm{MPa}$ for air drying, $100^{\circ} \mathrm{C}$ oven, and $80^{\circ} \mathrm{C}$ canola oil respectively. A Young's modulus of 733 $\mathrm{MPa}$ will be used for the evaluation of piezoelectric coefficients. The thickness of JB Weld between the steel stock and PVDF was appreciable while the JB Weld between PVDF prints was not.

Post poling tests showed that the unimorph device generates a decaying sinusoidal voltage with an initial peak-peak response of $2 \mathrm{~V}_{\mathrm{pp}}$ given an oscilloscope impedance of 10 MOhm. Next the sample was put under the microscope and a voltage of 1 and $2 \mathrm{kV}$ was applied. The deflections of 5.0 and $10.1 \mu \mathrm{m}$ were observed for the $1,000 \mathrm{~V}$ and $2,000 \mathrm{~V}$ tests. Using a modified version of Eq 5 for a 3-layer beam, an average $d_{31}$ coefficient of $1.19 \mathrm{pm} / \mathrm{V}$ was found for these specimens.

\section{Discussion}

Based on FTIR results, colder extrusion temperatures produced larger $\beta$-phase peaks at the expense of interlayer material adhesion. The film surfaces also tended to be rougher than higher temperature extrusions, which would be problematic for making continuous contact with a subsequently deposited electrode. Conversely, if the line widths were appropriately spaced, the surface of higher temperature extrusions could be made very smooth. With PVDF, if the extrusion line width is too compact (overlapping, thus to nullify void space) then the material tends to ride up on the previous line creating an out-of-plane wave that continuously propagates onto the proceeding lines. The authors attribute this effect to the high viscosity of molten PVDF [34], [35].

The effective Young's modulus for the 3D printed Kynar 740 was highest when the extrudate was parallel with the axial loading direction of the specimen. This result is expected as the continuous extrusion direction act similarly to the fiber orientation in composite materials. Similarly, the weakest direction for the 3D printed films was transverse to the extrusion direction. Poisson's ratio derived via DIC for the $0^{\circ}$ case is also explained by the perpendicular forces causing fused zones to strain more, thus giving a lower Young's modulus. The overall lower Young's modulus values found for printed PVDF sheets ( 0.4-0.5 GPa) compared to bulk literature values $(1.7-3 \mathrm{GPa})$ is somewhat expected as the structure of the FFF printed sheets has a higher porosity than bulk specimens (in terms of gaps made by extruding line by line and trapped voids in the material itself). It is also reiterated that the number of samples tested for each variable is too small to make the results statistically significant.

The $\beta$-phase content of PVDF films was influenced most significantly by the deposition speed, hot end temperature, and bed material. Of these factors, printing speed was the most significant. While fast printing speeds likely induce more $\beta$-phase due to mechanical strains, a much slower printing speed may provide benefits related to the time that the printed material is 
subjected to an electric field. Ideally, the material should be drawn at a high rate and remain under the poled electric field until it cools to a point where the aligned dipoles are unable to randomize. The flat nozzle setup was expected to resolve this issue, but was found to induce residual stresses sufficient to delaminate the PVDF film and curl onto the nozzle at higher speeds. If a better bed material could be used that would promote superior adhesion to that of hot brass, then flat nozzles might become viable. Currently the printing speeds used herein do not appear to provide sufficient time for the alignment of dipoles to occur for in-situ electrical poling during printing. This does not preclude alternative combinations of printing speed and electrical poling from potentially useable piezoelectric printed high $\beta$-phase PVDF films.

One potential avenue for reaching more efficient piezoelectric properties may be through higher applied electrical fields during printing, which were limited in this study by the current hot end set-up. Applying higher temperatures during electrical poling also increased $\beta$-phase. It is conceivable that much higher applied nozzle voltages coupled with higher temperatures would increase the piezoelectric potential and also expand the poling range of the hot end. One concern that arises when pushing the upper limits of the applied in-situ electrical field is arcing between the hot end and the grounded bed, which can disrupt serial communications between the computer and the printer. This issue was found to occur in this work at about 1,500 volts when using the 3M Blue Tape and about 3,000 volts when the positive electrode was touched to the Kapton tape. Any small rips or tears in the adhesion/isolation layer can cause immediate serial communication failure, so care was taken not to process on any worn portions of the bed.

FTIR-ATR results show that crystalline phases on the bottom of the PVDF samples have lower amounts of $\beta$ phase, independent of the bed material choice. This is most likely because the PVDF sticks to the bed and is then unable to be strained at that surface. Thus $\beta$-phase content is most likely not constant throughout the layer height. Since the ATR only measures attenuation a small fraction into the surface, it is able to observe this effect. $\beta$-phase promotion via strain is theorized then to have a parabolic profile where the maximum $\beta$ content is located at the top of the sample surface nearest the nozzle.

Like [36] promotion of $\beta$-phase relies on high pressures, stretching, additives, quenching, etc. Many of the results presented here follow the same trend, though many cannot be directly incorporated due to the nature of FFF additive manufacturing. Quenching the extrudate for example should help form more $\beta$ but could also cause premature warping of the film because of high thermal coefficient of expansion values. Stretching is a difficult problem since the designed film, if it were to be incorporated with an autonomous multipart build, would be vastly different in geometry. Additives like salt and ceramics could be done at the filament construction phase and at this point seem like the next area to exploit.

Stretching of the films is not conventional in FFF printing but is, in a way, mimicked. As [37] shows for very thin $\alpha$-films, stretching to ratios of up to five times the original length at elevated temperatures $\left(80-140^{\circ} \mathrm{C}\right)$ give large amounts of $\beta$. Extrusion of PVDF filament does strain the material and higher feed speeds show larger $\beta$ amounts. Which could mean that even faster feed rates would lend even more $\beta$-phase.

It should be noted that the copolymer poly[(vinylidenefluoride-co-trifluoroethylene] or $\mathrm{P}(\mathrm{VDF}-\mathrm{TrFe})$ has a high $\beta$-phase stable condition during solidification. It has been used in inkjet printing [38] and spin casted [17] sensors/actuators with great success. The largest disadvantage this copolymer has is cost, which sits at about $\$ 4,600 / \mathrm{kg}$ currently (PiezoTech, Arkema). To put this in perspective, 10 lbs of Kynar 740 costs about $\$ 300$ (or \$66/kg) from Trident Plastics, PA. 
Another potential path to higher $\beta$-phase parts is not through the processing of the final feed extrudate, but on the mechanical and thermal processing of the filament beforehand. Extrusion, quenching, and drawing of PVDF monofilament from [39] shows that high amounts of $\beta$-phase $(\sim 95 \%)$ are induced after processing. Though post processing the filament into a 3D printed form will significantly convert most of this $\beta$-phase to $\alpha$ via melting.

Similar to the efforts of [13], a post-deposition electrical poling was required to align the dipoles. Single layer samples could be post poled, though the area of poling was quite small. This was due to shorting between layers via small holes in the printed extradite. To obtain an appreciable thickness to length ratio, a double-layered PVDF sample was made to create a unimorph. Poling voltages were considerably high but the thickness of PVDF means the electric field during poling is on the low side of conventional poling methods $(\sim 10 \mathrm{MV} / \mathrm{m})$. If elimination of the small holes during printing can be achieved, then higher poling fields like 80 to $100 \mathrm{MV} / \mathrm{m}$ could be attempted, likely producing better piezoelectric coefficients.

\section{Conclusions}

Young's Modulus for the 3D printed PVDF samples are 457 and $486 \mathrm{MPa}$ on average for Shimadzu and DIC experiments. Poisson's ratio was found to be an average of 0.305 using DIC. Yield strength was highest when the infill was aligned to the pulling axis and reduces with reducing infill angle. Poisson's ratio is lowest for single layer extrusions when the force is parallel with the extrusion path.

PVDF $\beta$-phase may significantly increase in 3D printed samples by stretching and poling under a corona field. Lower temperature extrusions of $170^{\circ} \mathrm{C}$ had very high $\beta$-phase content but interlayer adhesion was weak and had a rough texture. High temperature extrusion had lower $\beta$ phase but stronger adhesion and smoother textures if the PVDF line widths are appropriate.

Bed material, such as the $3 \mathrm{M}$ Blue Painters Tape, was more porous and gave more $\beta$ phase at room temperature in the samples versus the Kapton tape at $100^{\circ} \mathrm{C}$. Breakdown voltage was about 1,000 volts using Blue Tape and printing samples at $250 \mu \mathrm{m}$ layer heights. The breakdown voltage for Kapton was not evaluated because arcing from the hot end to the thermistor lines happened first at 2,500 volts, which required a hardware exchange.

Higher horizontal speed extrusions increased $\beta$-phase. Smooth extrusions were only viable using the sharp nozzle due to bad adhesion and curling using the flat nozzle. Voltage enhanced $\beta$-phase content but only for the higher temperature samples. Applied voltage during extrusion did not align enough dipoles in the PVDF to obtain an appreciable charge during testing.

Electrical poling in an $80^{\circ} \mathrm{C}$ oil bath of relatively high $\beta$-phase content printed PVDF films at a field of $8.33 \mathrm{MV} / \mathrm{m}$ produced a repeatable, albeit small, piezoelectric coefficient $\mathrm{d}_{31}$ of $1.19 \mathrm{pm} / \mathrm{V}$.

\section{Acknowledgments}

The author would like to thank Dr. William Richmond in the Chemical Engineering Department at the University of Louisville for his help and support with FTIR data collection during this project. In addition, portions of this work have been funded in part by the National Science Foundation, Award \#1408005 through the EPNC program within the ECCS Division. 


\section{References}

[1] John R. Tumbleston, David Shirvanyants, Nikita Ermoshkin, Rima Janusziewicz, Ashley R. Johnson, David Kelly, Kai Chen, Robert Pinschmidt, Jason P. Rolland, Alexander Ermoshkin, Edward T. Samulski, and Joseph M. DeSimone. Continuous liquid interface production of 3d objects. Science, 347(6228):1349-1352, 2015.

[2] John Klein, Michael Stern, Giorgia Franchin, Markus Kayser, Chikara Inamura, Shreya Dave, James C. Weaver, Peter Houk, Paolo Colombo, Maria Yang, and Neri Oxman. Additive manufacturing of opoptical transparent glass. 3D P, 2(3):92-105, 2015.

[3] V.T. Rathod, D. Roy Mahapatra, Anjana Jain, and A. Gayathri. Characterization of a large-area PVDF thin film for electro-mechanical and ultrasonic sensing applications. Sensors and Actuators A: Physical, 163(1):164 - 171, 2010.

[4] Qin Chen, Don Natale, Bret Neese, Kailiang Ren, Minren Lin, QM Zhang, Matthew Pattom, KW Wang, Houfei Fang, and Eastwood Im. Piezoelectric polymers actuators for precise shape control of large scale space antennas. In The 14th International Symposium on: Smart Structures and Materials \& Nondestructive Evaluation and Health Monitoring, pages 65241 65241. International Society for Optics and Photonics, 2007.

[5] Vivek Bharti and R Nath. Piezo-, pyro- and ferroelectric properties of simultaneously stretched and corona poled extruded poly(vinyl chloride) films. Journal of Physics D: Applied Physics, 34(5):667, 2001.

[6] A. Salimi and Yousefi A. A. Ftir studies of $\beta$-phase crystal formation in stretched pvdf films. Polymer Testing, 22:699 - 704, 2003.

[7] Shuting Chen, Xue Li, Kui Yao, Francis Eng Hock Tay, Amit Kumar, and Kaiyang Zeng. Self-polarized ferroelectric PVDF homopolymer ultra-thin films derived from LangmuirBlodgett deposition. Polymer, 53(6):1404 - 1408, 2012.

[8] Ivo B Rietveld, Kei Kobayashi, Takuya Honjo, Kenji Ishida, Hirofumi Yamada, and Kazumi Matsushige. Electrospray induced ferroelectricity in poly (vinylidene fluoride) thin films. Journal of Materials Chemistry, 20(38):8272 - 8278, 2010.

[9] V F Cardoso, G Minas, C M Costa, C J Tavares, and S Lanceros-Mendez. Micro and nanofilms of poly(vinylidene fluoride) with controlled thickness, morphology and electroactive crystalline phase for sensor and actuator applications. Smart Materials and Structures, 20(8):087002, 2011.

[10] Subramaniyan Ramasundaram, Sun Yoon, Kap Jin Kim, and Jong Soon Lee. Direct preparation of nanoscale thin films of poly(vinylidene fluoride) containing B-crystalline phase by heat-controlled spin coating. Macromolecular Chemistry and Physics, 209(24):2516 - 2526, 2008.

[11] Kanguk Kim, Wei Zhu, Xin Qu, Chase Aaronson, William R. McCall, Shaochen Chen, and Donald J. Sirbuly. 3d optical printing of piezoelectric nanoparticle polymer composite materials. ACS Nano, 8(10):9799 - 9806, 2014. PMID: 25046646.

[12] ChaBum Lee and Joshua A Tarbutton. Electric poling-assisted additive manufacturing process for pvdf polymer-based piezoelectric device applications. Smart Materials and Structures, 23(9):095044, 2014. 
[13] Yixiang Bian, Rongrong Liu, Xiaomei Huang, Jin Hong, Huiyu Huang, and Shen Hui. Design and fabrication of a metal core pvdf fiber for an air flow sensor. Smart Materials and Structures, 24(10):105001, 2015.

[14] Matt Saari, Cox Bryan, Richer Edmond, Paul Kruegar, and Adam Cohen. Fiber encapsulation additive manufacturing: An enabling technology for $3 \mathrm{~d}$ printing of electromechanical devices and robotic components. 3D Printing and Additive Manufacturing, 2(1):32 - 39, March 2015.

[15] A Bandyopadhyay, RK Panda, TF McNulty, F Mohammadi, SC Danforth, and A Safari. Piezoelectric ceramics and composites via rapid prototyping techniques. Rapid Prototyping Journal, 4(1):37-49, 1998.

[16] S.M. Gaytan, M.A. Cadena, H. Karim, D. Delfin, Y. Lin, D. Espalin, E. MacDonald, and R.B. Wicker. Fabrication of barium titanate by binder jetting additive manufacturing technology. Ceramics International, 41(5, Part A):6610 - 6619, 2015.

[17] Hong-Jie Tseng, Wei-Cheng Tian, and Wen-Jong Wu. P(VDF-TrFE) polymer-based thin films deposited on stainless steel substrates treated using water dissociation for flexible tactile sensor development. Sensors, 13(11):14777 - 14796, 2013.

[18] Nathan Jackson, Rosemary O'Keeffe, Finbarr Waldron, Mike O'Neill, and Alan Mathewson. Influence of aluminum nitride crystal orientation on mems energy harvesting device performance. Journal of Micromechanics and Microengineering, 23(7):075014, 2013.

[19] H Han, Y Nakagawa, Y Takai, K Kikuchi, S Tsuchitani, and Y Kosimoto. Microstructure fabrication on a B-phase PVDF film by wet and dry etching technology. Journal of Micromechanics and Microengineering, 22(8):085030, 2012.

[20] Modern Plastics and Charles A. Harper. Modern Plastics Handbook. McGraw-Hill, 2000.

[21] Robert Dunsch and Jean-Marc Breguet. Unified mechanical approach to piezoelectric bender modeling. Sensors and Actuators A: Physical, 134(2):436 - 446, 2007.

[22] J Scheinbeim, C Nakafuku, BA Newman, and KD Pae. High-pressure crystallization of poly (vinylidene fluoride). Journal of Applied Physics, 50(6):4399-4405, 1979.

[23] Z Bashir and A Keller. Melt drawing as a route to high performance polyethylene. Colloid and Polymer Science, 267(2):116-124, 1989.

[24] J Wang, H Li, J Liu, Y Duan, S Jiang, and Yan S. On the alpha $\rightarrow$ beta transition of carbon-coated highly oriented pvdf ultrathin film induced by melt recrystallization. Journal of American Chemical Society, 125(6):1496-1497, Feb 2003.

[25] Paul Aquino. Piezoelectric flexing and output voltage of a microchannel heat engine. Master's thesis, University of Ontario Institute of Technology, 2010.

[26] Mel Schwartz, editor. Smart Materials. CRC Press, 2008.

[27] www.matbase.com.

[28] CG Duan, WN Mei, JR Hardy, S Ducharme, J Choi, and PA Dowben. Comparison of the theoretical and experimental band structure of poly(vinylidene fluoride) crystal. Europhys Lett., (61):81 - 87, 2003.

[29] Marcel Benz, William B Euler, and Otto J Gregory. The role of solution phase water on the deposition of thin films of poly (vinylidene fluoride). Macromolecules, 35(7):2682-2688, 2002.

[30] Behzad Mohammadi, Ali Akbar Yousefi, and Samad Moemen Bellah. Effect of tensile strain rate and elongation on crystalline structure and piezoelectric properties of PVDF thin films. Polymer Testing, 26(1):42 - 50, 2007. 
[31] Xujiang He and Kui Yao. Crystallization mechanism and piezoelectric properties of solution-derived ferroelectric poly(vinylidene fluoride) thin films. Applied physics letters, 89(11):112909, 2006.

[32] Rui Song, Guangmei Xia, Xueqing Xing, Linghao He, Qiaoling Zhao, and Zhi Ma. Modification of polymorphisms in polyvinylidene fluoride thin films via water and hydrated salt. Journal of colloid and interface science, 401:50 - 57, 2013.

[33] Liu Wen, Han MengDi, Meng Bo, Sun XuMing, Huang XianLiang, and Zhang HaiXia. Low frequency wide bandwidth MEMS energy harvester based on spiral-shaped PVDF cantilever. Sci China Ser E, 57(6):1068 - 72, 2014.

[34] Witold Brostow, Tomasz Sterzynski, and Sébastian Triouleyre. Rheological properties and morphology of binary blends of a longitudinal polymer liquid crystal with engineering polymers. Polymer, 37(9):1561 - 1574, 1996.

[35] Sina Ebnesajjad. Fluoroplastics: Melt Processible Fluoroplastics: The Definitive User's Guide (Fluoropolymers), volume 2. William Andrew Publishing, 2015. pg 263.

[36] P Martins, AC Lopes, and S Lanceros-Mendez. Electroactive phases of poly (vinylidene fluoride): determination, processing and applications. Progress in polymer science, 39(4):683 706, 2014.

[37] J Gomes, J Serrado Nunes, V Scencadas, and Lanceros. Influence of the $\beta$-phase content and degree of crystallinity on the piezo- and ferroelectric properties of poly(vinylidene fluoride). Smart Materials and Structures, 19(6):065010 (7pp), 2010.

[38] Rubaiyet Iftekharul Haque, Rémy Vié, Michel Germainy, Laurie Valbin, Patrick Benaben, and Xavier Boddaert. Inkjet printing of high molecular weight pvdf-trfe for flexible electronics. Flexible and Printed Electronics, 1(1):015001, 2015.

[39] M.P. Silva, R.S. Martins, H. Carvalho, J.M. Nobrega, and S. Lanceros-Mendez. Extrusion of poly(vinylidene fluoride) recycled filaments: Effect of the processing cycles on the degree of crystallinity and electroactive phase content. Polymer Testing, 32(6):1041 - 1044, 2013. 